\title{
Do Islamic Indices Provide Diversification to Bitcoin? A Time-Varying Copulas and Value at Risk Application
}

\author{
Mobeen Ur Rehman \\ Informetrics Research Group, Ton Duc Thang University, Ho Chi Minh City, Vietnam \\ Faculty of Social Sciences and Humanities, Ton Duc Thang University, Ho Chi Minh City, Vietnam \\ Email:MobeenRehman@live.com

\section{Nadia Asghar} \\ Department of FASE, Business School, Faculty of Arts, Business \& Social Sciences, University of \\ Wolverhampton, Wolverhampton, $U K$. \\ Email:N.Asghar3@wlv.ac.uk \\ Sang Hoon Kang \\ Department of Business Administration, Pusan National University, Busan 609-735, Republic of \\ Korea \\ School of Commerce, UniSA Business School, Adelaide, South Australia 5001 \\ Email: sanghoonkang@pusan.ac.kr
}

\section{Acknowledgment:}

This work was supported by the Ministry of Education of the Republic of Korea and the National Research Foundation of Korea (NRF-2017S1A5B8057488). 


\title{
Analyzing the risk dependence between Islamic indices and Bitcoin: A timevarying Copula and CoVaR approach
}

\begin{abstract}
The emergence of new asset classes offers avenues to international investment community however understanding relationship between any two assets in a single portfolio is important. We investigate the risk dependence between daily Bitcoin and major Islamic equity markets spanning over from July 2010 to March 2018. We start by examining long memory properties of Bitcoin and sampled Islamic indices and report significant results. The residuals from fractionally integrated models are then used in bivariate time invariant and time varying copulas to investigate dependence structure. Among all Islamic indices, DJIUK, DJIJP and DJICA exhibit time varying dependence with Bitcoin. Finally, we apply VaR, CoVaR and $\square \mathrm{CoVaR}$ as risk measure to examine spillover between Bitcoin and Islamic equity markets. VaR of Bitcoin exceeds from VaR of Islamic indices and $\mathrm{CoVaR}$ of both Islamic and Bitcoin exceeds their respective $\mathrm{VaR}$, suggesting presence of risk spillover between each other. Our results also report asymmetry between downside and upside $\mathrm{CCoVaR}$ suggesting implications for investors with different risk preferences.
\end{abstract}

Keyword: Bitcoin; Islamic indices; Long memory; Copulas; Value at Risk.

\section{Introduction}

An increasing number of financial assets attributable to financialization of different commodities, currencies etc. has led investors and researchers to investigate the underlying patterns between these different asset classes. This is because no matter how profitable a single security becomes, its relationship with other assets in a portfolio needs to be evaluated in order to earn optimal portfolio returns. The increasing number of investment options for investors are paving way for modern innovations in finance (see for example Muli and Joaongo, 2019). Due to distinctive risk and return features, investments in alternative assets are getting popular among investors and market makers (Lahmiri and Bekiros, 2018). Recent era of market turmoil has also motivated the institutional and individual investor to look beyond traditional investments such as bonds and shares (Cumming et al., 2014). Assets, like gold, crypto currencies and Islamic equites, 
with superior hedging characteristics against traditional asset markets have gained attention for empirical contribution on diversification of risk and return trade-off (Lim and Masih, 2017; Kenourgios et al., 2016; Evans, 2015).

Financial markets turbulence in last two decades created need for alternative investment assets; which resulted in recognition to Islamic stock markets and formation of crypto currency market, among others (Mensi et al., 2018). Crypto currency is a result of innovation in payment system from 1980's (Tschorsch and Scheuermann, 2016; Nakamoto, 2008) which because of underlying block chain technology, assumed incapable of swindling investors (Vigna and Casey, 2015). Therefore, crypto currency is widely accepted and used as a digital investment asset for medium of exchange and speculations (Ali et al., 2014). Since the inception of bitcoin in 2009, 1500 different crypto currencies are announced and offered new ways of proliferation (Trimborn and Härdle, 2018). However, Bitcoin remains the most significant and leading crypto currency capturing more than $50 \%$ of coin market capitalization (Al-Yahyaee et al., 2018). ${ }^{1}$ It is been observed that market capitalization and turnover of crypto currency is increasing exponentially (ElBahrawy, et al., 2017) ${ }^{2}$ therefore, the Bitcoin has been classified as a commodity asset in the US (Kawa, 2015) and it has achieved the status of legal currency in Japan (EconoTimes, 2016). However, empirical analysis has shown that behaviour of crypto currencies is different from traditional currencies and commodities in terms of maturity, operating system, valuation, underlying assets and speculation (Mensi, 2018; Wang and Vergne, 2017; Yermack, 2015). Though bitcoin dominates crypto currencies but does not lead the crypto currencies' market, however, due to less co-movement with conventional equity markets, offers opportunities for

\footnotetext{
${ }^{1}$ https://coinmarketcap.com/charts/

${ }^{2}$ over $\$ 100$ billion
} 
portfolios diversification (Elendner et al., 2016; Tschorsch and Scheuermann, 2016). However, despite of potential diversification opportunities offered by Bitcoin due to low correlation with other asset classes, it observed 845\% growth from 2013 to mid-2018 (Kunita and Pattanayak, 2018), making researchers keen to learn more on behaviour and characteristics of crypto currencies (Aysan et al., 2019).

Islamic finance has observed tremendous growth in last decade. According to 2017 estimates, \$2.05 trillion are invested in Islamic finance and is continually growing with expectation to gain size of $\$ 6.5$ trillion by 2020 (Magyereh et al., 2019; Hammoudeh et al., 2014). Islamic equity market (IEM, here after) sustained the financial meltdown of 2008-09 and out beat the performance of conventional equity markets (Milly and Sultan, 2012; Hayat and Kraussl, 2011) which sparked investor`s interest in Sharia compliance products that prohibit interest and operates on the principles of profit and loss sharing (Hkiri et al., 2017; Nazlioglu et al., 2015). Islamic finance is based on the principles of Islamic law, which also prohibit gambling, derivatives, short selling and promotes risk sharing over risk shifting (Saâdaoui, 2017; Maghyereh and Awartani, 2016; Abbes, 2015). Due to these aforementioned features, IEM is considered as an alternative financial intermediation in assets markets as Sharia compliance assets (Magyereh et al., 2018; Shamsuddin, 2014). Islamic equity markets have appealed researchers, investor and regulators for risk diversification due to their size, continual growth and stable performance during and after recent financial crisis (Kenourgios et al., 2016; Najeeb, et al., 2015; Rizvi et al., 2015; Dewandru et al., 2014; Jawadi et al., 2014; Al-Khazli et al., 2014).

From recent studies (Mazouz et al., 2019; Shahzad et al., 2018; Mensi et al., 2018; Saâdaoui, 2017; Naifar, 2016), it is observed that financial modelling is motivated in determining the underlying association which connects the financial market across globe. Understanding the 
dynamics of this associations with structural dependence across financial markets is beneficial in assessing risk diversification and countering boom and bust of financial markets (Wang and Xie, 2016; Shahzad et al., 2017; Hammoudeh et al., 2014). Therefore, our contribution in this study is as follows.

First, both Islamic and crypto currency markets can play important role in portfolio diversification and mitigating financial catastrophes, due to their investment features and hedging characteristics, therefore, this study raises a question about how these two alternative markets are related to each other. Secondly, to the best of our knowledge, this study is the first attempt to examine the dependence structure between Bitcoin and seven major Islamic equity markets. ${ }^{3}$ Inclusion of such wide array of Islamic equity indices based on different regions provides more insights for international investment since Bitcoin speculative returns are anticipated regardless of any specific capital market. These two asset classes i.e. Islamic and Bitcoin markets have been used separately with former ought to possess hedging and diversification capabilities and later with huge returns to increase individual and cumulative portfolio gains. Third, considering turbulent behaviour of Bitcoin since its inception and asset backed behaviour of Islamic indices, we investigate long memory properties of both asset classes followed by identifying best dependence structure. These empirical tests follow measure for risk spillover consisting of $\mathrm{VaR}, \mathrm{CoVaR}$ and $\square \mathrm{CoVaR}$ in order to throw light on the capabilities of these assets to share returns' co-movements during extreme market conditions.

\footnotetext{
${ }^{3}$ Dow Jones Islamic Market (DJIM) Index, Dow Jones Islamic Market US technology (IMUS) Index, Dow Jones Islamic Market Europe (DJIEU) Index, Dow Jones Islamic Market Asia/Pacific (DJIAP) Index, Dow Jones Islamic Market U.K. (DJIUK) Index, Dow Jones Islamic Market Japan Index (DJIJP), and Dow Jones Islamic Market Canada Index (DJICA).
} 
Our results highlight the presence of long memory properties in Bitcoin and sampled Islamic equity indices. DJIUK, DJIJP and DJICA among others, exhibit time varying dependence structure with Bitcoin which requires a careful look at the return patterns of Bitcoin under extreme market conditions. Our application of risk measures includes VaR, CoVaR and $\Delta \mathrm{CoVaR}$. VaR of Bitcoin appears high compared with any of the Islamic equity markets. CoVaR measure of Bitcoin and Islamic indices appear high compared with their respective VaR suggesting potential for risk spillover between these two asset classes. We also report asymmetry between downside and upside $\Delta \mathrm{CoVaR}$ of Bitcoin as well as sampled Islamic indices.

The remainder of this paper is organised as follows. Section 2 presents the literature review. Section 3 describes the empirical methods. Section 4 provides data and preliminary statistics.

Section 5 reports and discusses empirical results. Section 6 concludes the paper.

\section{Literature Review}

Bitcoin among other crypto currencies, grabbed attention during the last couple of years as an investment opportunity and therefore, has evidence of ample discussion (see Ciaian, 2016; Dyhrberg, 2016a; Cheah and Fry, 2015; Kristoufek, 2015; Garcia et al., 2014; Moore and Christin, 2013). Existing literature also documents Bitcoin as a valuable investment (Bouri et al., 2017a; Baur et al., 2017; 2015) and for similar reason, is examined for its relationship with other assets. Among other studies, Rehman and Apergis (2019) report significant causality running from Bitcoin to commodity futures. Zhang et al. (2018) while analysing relationship of crypto currencies with conventional equity indices, report persistence in cross-correlation between Bitcoin and Dow Jones Industrial Average (DJIA). However, Bitcoin and traditional assets (stocks, bonds and currencies) are correlated neither in financial turmoil nor in normal times (Baur et al., 2018). Due to remarkable low correlation with traditional assets and an alternative asset, namely Bitcoin (Bouri et al., 2017a) 
and Briere et al. (2015) conclude that Bitcoin is suitable for portfolio diversification and improving risk and return trade-off in the US stock market. Bouri et al. (2017c) observe Bitcoin with strong hedging and safe heaven properties against commodity and energy indices. Dyhrberg (2016a; 2016b) report Bitcoin as a substitute of gold in hedging against UK stocks and US dollar. Bouoiyour and Selmi (2016) also confirmed Bitcoin as a safe haven for hedging market risk however only in short run. Bitcoin is examined for optimal asset allocation in portfolio construction and also tested as an alternative reserve currency (Ji et al., 2018; Rogojanu and Badea, 2014). Despite of theoretical and empirical contribution, literature still have room for comprehensive and comparative analysis on dynamics and movement of Bitcoin with

unconventional investment assets (ElBahrawy, et al., 2017).

Literature on Islamic finance has seen substantial contribution in last two decades. Islamic equity markets are rigorously reviewed by researchers for their characteristics (Álvarez-Díaz, 2014; Hayat and Kraussl, 2011), performance and comparative analysis with conventional finance (Ahmed and Elsayed, 2018; Narayan and Bannigidadmath, 2015; Wahyudi and Sani, 2014; Alam et al., 2013; Godlewski et al., 2013; Milly and Sultan, 2012; Abdullah et al., 2007), review of performance during and after financial crises (Kenourgios and Dimitriou, 2016; Aloui et al., 2015b; Dewandaru et al., 2014; Karim et al., 2012), risk diversification (Ahmad et al., 2018; Najeeb et al., 2015; Rizvi et al., 2015) and as social and ethical investments (Mazouz et al., 2019; Dania and Malhotra, 2013; Hussein and Omran, 2005). Islamic equities differ from conventional equity markets in terms of features, performance and returns. For example, Narayan and Bannigidadamath (2017) observed that financial news can better predict returns of Islamic equities compared to conventional investments. Hkiri et al. (2017) analysed conventional indices with nine regional Islamic indices and conclude that portfolio manager can use Islamic financial equities for portfolio diversification in order to hedge market risk which even act as safe heavens during 
turbulent market conditions. According to Kassab (2013), Islamic indices exhibit less volatile behaviour compared to conventional markets. Though Islamic equities are less efficient than conventional stocks, they outperform their conventional counterparts in terms of asset quality, capitalization and intermediation (Ashraf and Mohammad, 2014; Beck et al., 2013; Ho et al., 2013).

Though Islamic equity markets and Bitcoin have been an interesting topic for researchers, literature discussing both these asset classes within a single portfolio remains scarce. Evans (2015) did the first comparative analysis on Bitcoin management structure and Islamic banking and finance and report that both are compatible on the principles of Maslaha ${ }^{4}$ and mutual risk sharing. Lim and Masih (2017) analysed both markets and observe negative correlation between Shariah Stock indices and Bitcoin. They further suggest that Islamic fund managers should consider bitcoin for risk diversification in their investment decisions. Lahmiri et al. (2018) examined conventional, Islamic and socially responsible investments and find presence of long-range memory for all three investments. Though literature on empirical comparative analysis of Bitcoin and Islamic equity market is very thin, most of the discussion revolves around comparability (Muedini, 2018;

Alzubaidi and Abdullah, 2017) and compliance of Bitcoin with Sharia laws and rules (Bakar and Rosbi, 2018; Meera, 2018). In the spirit of shared literature, it is therefore of worth to empirically analyse, how Bitcoin and Islamic equites share extreme return movements with each other.

In terms of methodologies, different approaches are used to determine the nature of relationship among different financial markets. These mainly comprise but not limited to wavelet coherence analysis and vector autoregression (VAR) method (Mensi et al., 2018), generalised VAR

\footnotetext{
${ }^{4}$ Social benefits of positive externalities
} 
method (Hkiri et al., 2017), directed acyclic graph (Ji et al., 2017), pairwise dynamic correlationbased model (Bouri et al., 2017a), asymmetric dynamic conditional correlation (DCC) model (Bouri et al., 2017b), SVAR models (Hammoudeh et al., 2016), wavelet coherence and asymmetric causality method (Aloui et al., 2016), causality in variance test (Nazlioglu et al., 2015), wavelet decomposition (Rizvi et al., 2015; Dewandaru et al., 2014), copula approach (Hammoudeh et al., 2014), heteroscedasticity robust linear granger causality and non-linear causality test (Amji et al., 2014), GARCH model (Kassab, 2013), multivariate-GARCH model (Majdoub and Mansour, 2014; Akhtar et al., 2013) and co-integration test (Hakim and Rashidian, 2002), among others. Ali et al. (2018) examine conventional and Islamic stock markets efficiency using fractional integrated GARCH (FIGARCH) model and conclude that due to Sharia compliance and good governance, Islamic equity markets are more efficient than their conventional counterparts. Aloui et al. (2015a) investigate co-movement of Islamic equity market with Global Sukuk by employing DCCGARCH model and report time varying negative correlation with structural break points for extreme events. Existing strand of literature also documents evidence on the dependence structure between Islamic and unconventional equity Indices. For example, Hammoudeh et al. (2014) investigated dependence structure between global Islamic (DJIM) and conventional indices (US, Asia, Europe and global risk factor) using copula based GARCH model. Their results highlight that Islamic equity indexes have strong time varying dependence with their conventional counterparts. Similarly, Naifar (2016) and Amji et al. (2014) reported significant causality between Islamic (DJIM) and unconventional equity markets (US, Europe and Asia). Therefore, in lights of the aforementioned discussion, existing literature provides evidence that Islamic equity indices are not correlated with conventional indices, thereby providing effective portfolio diversification and superior hedging tool under periods of turmoil, both in developed and emerging markets (see 
Kenourgios et al., 2016; Mensi et al., 2015; Abbes et al., 2015; Al-Khazli et al., 2014; Majdoub and Mansour, 2014; Akhtar et al., 2016).

\section{Methodology}

\subsection{The marginal distribution model}

In order to examine the extreme dependence structure between the Islamic equity and Bitcoin markets, we consider the ARFIMA-FIGARCH model, a well-known parametric tool for testing dual long-memory properties in returns and volatility, simultaneously. The choice of the optimal lag order is based on the AIC information criterion. Following Hosking (1981), the $\operatorname{ARFIMA}\left(n, d_{m}, s\right)$ model can be expressed as:

$$
\begin{aligned}
& \Psi(L)(1-L)^{d_{m}}\left(r_{t}-\mu\right)=\Theta(L) \varepsilon t, \\
& \varepsilon_{t}=z_{t} \sqrt{\sigma^{2}} t, Z_{t} \sim N(0,1),
\end{aligned}
$$

where $r_{t}$ is the return for each time-series at time . $t \varepsilon_{t}$ is the independently distributed error with variance $\sigma^{2}$ t. $\Psi(L)=1-\Psi_{1} L-\Psi_{2} L^{2}-\cdots-\Psi_{n} L^{n}$, and $\Theta(L)=1+\Theta_{1} L+\Theta_{2} L^{2}+\cdots+\Theta_{s} L^{s}$ are, respectively, the autoregressive (AR) and moving-average (MA) polynomials for which all roots lie outside the unit circle and denotes the lag operator. The fractional integrated parameter $L$ $\left(d_{m}\right)$ measures the degree of persistence or long memory in the returns. ${ }^{5}$

\footnotetext{
${ }^{5}$ According to Hosking (1981), the process presents the following behaviors: (i) stationary and invertible if $r_{t}$ $-0.5<d_{m}<0.5$; (ii) stationary (or short memory) if $d_{m}=0$; a unit root process if $d_{m}=1$; (iii) long memory
} 
Similar research on volatility has extended the ARFIMA representation of $\varepsilon^{2} t$, the

FIGARCH $\left(1, d_{v}, 1\right)$ can be expressed as follows:

$$
\sigma^{2} t=\omega[1-\beta(L)]^{-1}+\left[1-[1-\beta(L)]^{-1} \phi(L)\left((1-L)^{d v}\right)\right] \varepsilon^{2} t
$$

where $\omega, \beta, \phi$, and $d_{v}$ are the parameters to be estimated. The parameter $d_{v}, 0 \leq d_{v} \leq 1$, measures the long range memory in the conditional volatility. When $0<d_{v}<1$, the FIGARCH model is sufficiently flexible to allow for a long memory process in volatility.

We assume that $\{z t\}$ follows a Hansen's (1994) skewed- $t$ density distribution which allows us to capture the tail thickness and skewness in return distribution. It is given by:

$$
\begin{aligned}
& 1 b z t+a 2-\left(\smile^{2}+21\right) \\
& \text { - } b c\left(1+v-2\left(1-\frac{}{1-} \quad k\right)\right) z \\
& f\left(z^{t}, v, k\right) \quad=_{(v+21)} \quad \text {, if } z_{t t} \geq<--a / b a / b \\
& 1 \quad b z t+a 2- \\
& b c(1+v-2(1+k))
\end{aligned}
$$

where and are the degree of freedom parameters $v k(2<v \leq \infty)$ and the skewness parameter ( $-1<k<1)$, respectively. The constants, , are given by: a $b$ c $a=4 k c\left(\frac{v-2}{v-1}\right) b^{2}=1+, 3 k-a^{2}$ between distant observations) if $-0.5<d_{m}<0$. 


$$
v+1 v \text { and } c=\Gamma(2) / \pi(v-2) \Gamma(2) \text {. If } k=0 \text { and } v \rightarrow \infty, \text { then the skewed Student- } t
$$

distribution converges to the standard Gaussian distribution, but if $k=0$ and is finite then the distribution $v$ becomes a standard Student-t distribution.

\subsection{Copula approach}

This study employs static and time-varying parameter bivariate copula methods to capture the extreme the upper and lower tail dependence between the pairs of the Islamic equity and Bitcoin markets. To estimate the copula and marginal density parameters, we apply Sklar's theorem (Sklar, 1959) which asserts a joint distribution $F_{X Y}(x, y)$ of two random variables and $X Y$ can be expressed as:

$$
F_{X Y}(x, y)=C(u, v)
$$

where $C(u, v)$ for $u=F_{X}(x)$ and $v=F_{Y}(y)$ is a bivariate copula function with uniform marginal distributions. It is uniquely determined for the ranks $\operatorname{Ran} F_{X} \times \operatorname{Ran} F_{Y}$ when the margins are continuous. In addition, the joint probability density $f_{X Y}(x, y)$ can be obtained from the copula density, $c(u, v)$ as:

$$
f_{X Y}(x, y)=c(u, v) f_{X}(x) f_{Y}(y)
$$

where $c(u, v)=\partial^{2} C(u, v) / \partial u \partial v$, and $f_{X}(x) f_{Y}(y)$ are the marginal densities of the $X$ and $Y$ variables. A copula provides an appropriate knowledge on average and extreme upward or lower co-movements, referring to tail dependence. The upper (right) and lower (left) tail dependence can be computed from the copulas as follows: 


$$
\tau^{U}=\lim \operatorname{Pr}\left[X \geq F{ }^{-} X^{1}(u) \mid Y \geq F{ }^{-}{ }^{1}(u)\right]=\lim 1-2 u_{1}{ }_{-} u^{C(u, u)}
$$
(7)

$$
u \rightarrow 1 \quad u \rightarrow 1
$$

$$
\tau^{L}=\lim _{u \rightarrow 1} \operatorname{Pr}\left[X \leq F{ }^{-} X^{1}(u) \mid Y \leq F{ }^{-} Y^{1}(u)\right]=\lim _{u \rightarrow 1} \overline{C_{1}\left(u, u_{-u}\right)}
$$

where $F^{-}{ }^{1}$ and $F^{-}{ }^{1}{ }^{1}$ are the marginal quantile functions and $\tau^{U}, \tau^{L} \in[0,1]$. The lower (upper) tail dependence implies that $\tau^{U}>0\left(\tau^{L}>0\right)$, indicating a non-zero probability of observing an extremely small (or large) value for one series together with an extremely small (or large) value for another series.

In this paper, we implement various types of static and time-varying parameter bivariate copula functions with systemic and asymmetric dependence structures. As for the symmetric copulas, bivariate copulas include Normal copula, Student's-t copula, Frank copula and Plackett copula with equal a lower and upper tail dependence. The asymmetric copulas are the Gumbel (rotated Gumbel) copula which is designed to asymmetrically account for upper (lower) tail dependence and lower (upper) tail independence, Clayton (rotated Clayton) copulas with an upper (lower) tail independence and lower (upper) tail dependence and the symmetrized Joe-Clayton copula (SJC) with a special case of the symmetric tail dependence. For mathematical specifications, the reader can refer to Liu et al., (2017) and Shahzad et al. (2018).

In addition, we consider the time-varying parameter copula in terms of a specific evolution equation. For the Gaussian and the Student's-t copulas, the evolution of linear dependence parameter $\rho_{t}$ follow an ARMA(1,q)-type process (Patton, 2006). 


$$
\rho_{t}=\Lambda\left(\psi_{0}+\psi_{1} \rho_{t-}{ }^{1}+\psi_{2} \frac{1}{q} \sum_{j=1}^{q} \Phi^{-1}\left(u_{t-j}\right) \cdot \Phi^{-1}\left(v_{t-j}\right)\right)
$$

where $\Lambda(x)=\left(1-e^{-x}\right)\left(1+e^{-x}\right)^{-1}$ is the modified logistic transformation that ensures the value of $\rho_{t}$ in $(-1,1)$. Hence, the dependence parameter is determined by the constant $\psi_{0}$, the autoregressive tem $\psi_{1}$, and parameter for average product over the last $q$ observations of transformed variables $\psi_{2}$. The dynamic time-varying parameter of Student's-t copula can be explained by $\rho_{t}$ in Eq. (9) when a standard normal quantile function $\Phi^{-1}(x)$ is substituted by $t^{-} t^{1}$ $(x)$.

The dynamic time-varying parameters of Gumbel and rotated Gumbel copulas follow the $\operatorname{ARMA}(1, q)$ process specified as:

$$
\delta_{t}=\omega+\beta \delta_{t-1}+\alpha_{q}^{1 q} \sum_{j=1} \mid u_{t-j-v_{t-j} \mid}
$$

In a similar way, the evolution of SJC copula tail dependence parameters is assumed according to:

$$
\begin{aligned}
& \tau_{t}^{U_{t}}=\Delta\left(\omega U+\beta_{U} \rho_{t-1}+\alpha_{U}{ }_{q} \sum^{q_{j=1}}\left|u_{t-j}-v_{t-j}\right|\right) \\
& \tau^{L_{t}}=\Delta\left(\omega_{L}+\beta_{L} \rho_{t-1}+\alpha_{L}{ }_{q} \sum^{q_{j=1}}\left|u_{t-j}-v_{t-j}\right|\right)
\end{aligned}
$$

where $\Delta(x)=\left(1+e^{-x}\right)^{-1}$ is the logistic transformation to keep $\tau^{U_{t}}$ and $\tau^{L} t$ within interval $(0,1)$. 


\subsection{Systemic risk measures: down side and upside VaRs and CoVaRs}

In this section, we compute both the downside and upside VaRs and CoVaRs for Islamic equity and Bitcoin pairs. VaR is the most popular tool to measure investors' maximum losses within a specific time horizon and with a confidence level by holding a long position (i.e., downside risk) or a short position (i.e., upside risk). However, $\mathrm{VaR}$ is not possible to account for possible risk spillover between markets. CoVaR overcomes this VaR's shortcoming by providing information on the VAR of a market, conditional on the fact that another market is in financial stress (Reboredo and Ugolini, 2015).

The downside (upside) VaR at time and for a confidence level t $\quad 1-\alpha$ is given by $\mathrm{Pr}$ $\left(r_{t} \leq \operatorname{Va} a_{\alpha, t}\right)=\alpha\left(\operatorname{Pr}\left(r_{t} \geq \operatorname{VaR} 1_{-\alpha, t}\right)=\alpha\right)$. The downside and upside VaR can be expressed as:

$$
\begin{aligned}
& \operatorname{VaR}_{\text {Downside }_{\alpha, t}}=\mu_{t}+t_{v, k^{-1}}(\alpha) \sigma_{t} \\
& \operatorname{VaR}_{\text {Upside }_{\alpha, t}}=\mu_{t}+t_{v, k^{-1}}(1-\alpha) \sigma_{t}
\end{aligned}
$$

when $\mu_{\mathrm{t}}$ and $\sigma_{\mathrm{t}}$ are the conditional mean and standard deviation of the return series, computed though the mean and variance equation of the ARFIMA-FIGARCH model as modeled in Eqs. (1)(3), and where $t_{v, k^{-1}}(\alpha)$ denotes the -quantile of the skewed Student-t distribution in Eq. (4). $\alpha$

Furthermore, we utilize the CoVaR risk measure, as proposed by Girardi and Ergün (2013) to consider the impact of financial distress in Islamic equity markets as measured by its $\mathrm{VaR}$ on the VaR of the Bitcoin market and vice versa. The CoVaR is defined as the VaR of asset $i$ conditional on that fact asset suffers from an extreme movement. Let be the returns for Islamic $j$ 
$r_{t}{ }^{I}$ equity markets and $r^{B}$ be the returns for the Bitcoin market. The downside CoVaR for Islamic equity returns for an extreme downward Bitcoin returns and a confidence level $1-\beta$ can be formally expressed as the -quantile of the conditional distribution of $\beta \quad r_{t}{ }^{I}$ as:

$$
\operatorname{Pr}\left(r_{t}^{I} \leq \operatorname{CoVaR}_{\beta, t^{I}} \mid r^{B} t \leq \operatorname{VaR} \alpha, t^{B}\right)=\beta,
$$

where $\operatorname{CoVaR} \beta, t^{I}$ denotes the downside conditional VaR of equity returns with confidence level (1 $-\beta$ ), which is the -quantile of a conditional distribution, and where $\beta \quad \operatorname{VaR} \alpha, t^{B}$ is the -quantile $\alpha$ of return distribution. Similarly, we can quantify upside risk spillover as:

$$
\operatorname{Pr}(r t I \geq \operatorname{CoVaR} \beta, t I \mid r B t \geq \operatorname{VaR} 1-B \alpha, t)=\beta,
$$

where $\mathrm{CoVaR}_{\beta, t}{ }^{I}$ and $\mathrm{VaR}_{1-}{ }^{B}, t$ denote the upside conditional $\mathrm{VaR}$ and the upside VaR of Islamic equity and Bitcoin returns, respectively. We can use the copula presentation to measure the systematic impact of an Islamic equity on Bitcoin by considering the CoVaR in Eqs (15)-(16) which can be expressed as:

$$
\begin{gathered}
C\left(F_{r t l}\left(\operatorname{CoVaR}_{\beta, t} t^{\prime}\right), F_{r B t}\left(\operatorname{VaR}_{\alpha, t^{B}}{ }\right)\right)=\alpha \beta \\
1-F_{r t l}(\operatorname{CoVaR} \beta, t I)-F_{r B t}(\operatorname{VaR} 1-B \alpha, t)+C\left(F_{r t I}(\operatorname{CoVaR} \beta, t I), F_{r B t}(\operatorname{VaR} 1-B \alpha, t)\right)=\alpha \beta
\end{gathered}
$$

where $F_{r t}$, and $F_{r B_{t}}$ are the marginal distributions of Bitcoin returns and Islamic equity returns, respectively. 
In order to test for the significance of downside (upside) risk spillovers, we utilize the Kolmogorov-Smirnov (KS) bootstrapping test of Abadie (2002) to compare the cumulative distribution for downside (upside) CoVaR and VaR values. The KS test measures the difference between two cumulative quantile functions relying on the empirical distribution function but without considering any underlying distribution function. It is defined as:

$$
\begin{gathered}
m n \quad 1 / 2 \\
K S_{m n}=\left(\overline{(m+n)} \operatorname{Sup}_{x}\left|F_{m}(x)-G_{n}(x)\right|,\right.
\end{gathered}
$$

where $F_{m}(x)$ and $G_{n}(x)$ are the cumulative $\mathrm{CoVaR}$ and $\mathrm{VaR}$ distribution functions, respectively, and and $n m$ are the size of the two samples. We test the hypothesis of equality or no systemic impact from Bitcoin to Islamic equity markets as:

$$
H_{0}: \operatorname{CoVaR}_{\beta, t^{I}}=\operatorname{VaR}_{\beta, t^{I}} . H_{1}: \operatorname{CoVaR}_{\beta, t^{I}}<\operatorname{VaR}_{\beta, t^{I}},
$$

\section{Data and Preliminary analysis}

\subsection{Data}

This study uses daily closing spot prices for seven Islamic equity prices indices. The indices include Dow Jones Islamic Market (DJIM) Index, Dow Jones Islamic Market US technology (IMUS) Index, Dow Jones Islamic Market Europe (DJIEU) Index, Dow Jones Islamic Market Asia/Pacific (DJIAP) Index, Dow Jones Islamic Market U.K. (DJIUK) Index, Dow Jones Islamic Market Japan Index (DJIJP), and Dow Jones Islamic Market Canada Index (DJICA). The sample period runs from July 2010 to March 2018. It covers several episodes of widespread instabilities 
and crises (e.g., the 2010-2012 European debt crisis, 2013 US FRB taper tantrum, 2015 Chinese stock market collapse, and 2016 Brexit, etc.), and the gradual recovery of the global stock markets. Data for all the index series are extracted from Bloomberg. We also consider daily spot price of Bitcoin (BTC), covering similar sampling period like Islamic indices. Data for Bitcoin is sourced from the Coindesk Price Index website for Bitcoin. In applying the ARFIMA-FIGARCH model, we convert the price series data into continuously compounded returns, and for copula modeling we estimate copula data that lies in $[0,1]$.

Figure 1 displays the price dynamics of the Bitcoin and Islamic equity indexes. For most of the Islamic series, we witness consistent increase in pricing throughout the sample period except DJIUK and DJICA. DJIUK exhibits persistent pricing across the sample period without any major price hike however DJICA follows a consistent decline after 2010. Unlike all the Islamic indices, Bitcoin follows sharp escalation in 2017 which keeps its momentum till the year end however after which it exhibits sharp decline. This pricing behavior reflects the inconsistent and speculative behavior of Bitcoin thus the need for investors to hedge this asset class with more persistent returns' dynamics. 


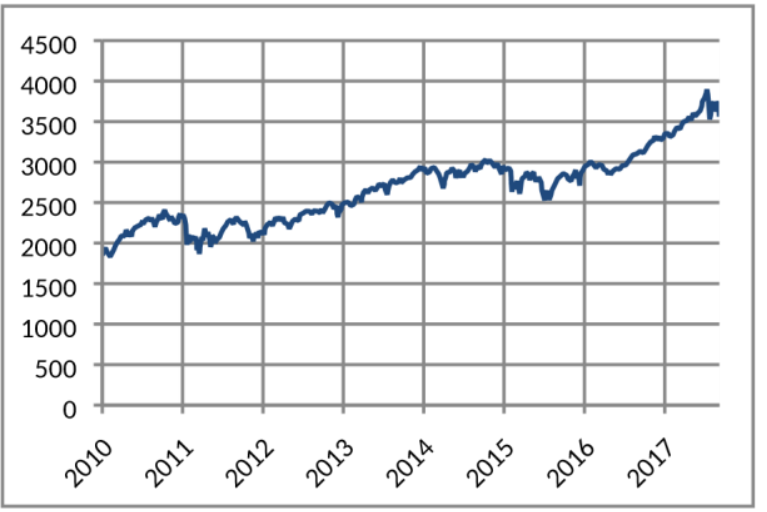

a) DJIM

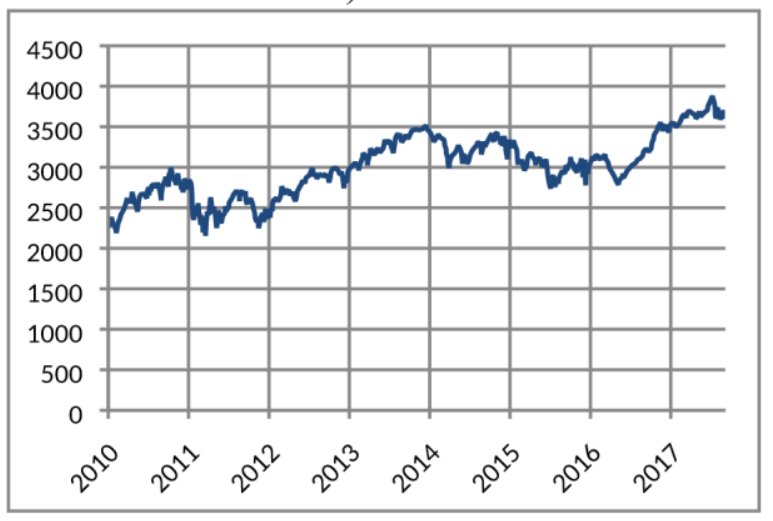

c) DJIEU

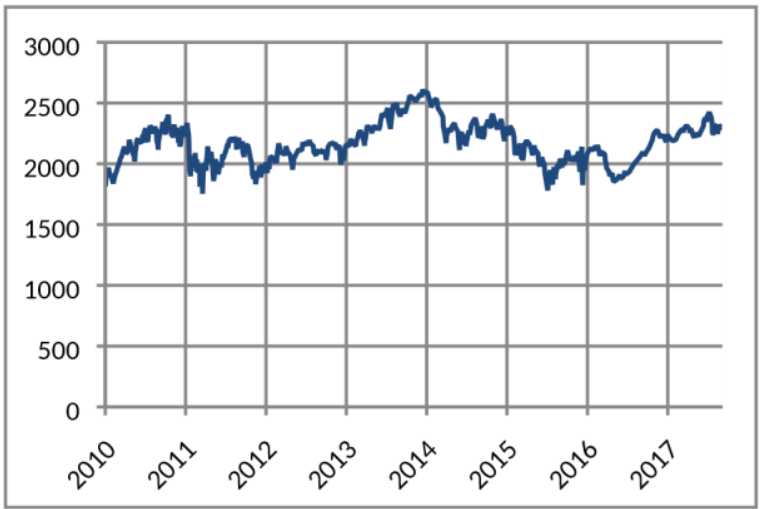

e) DJIUK

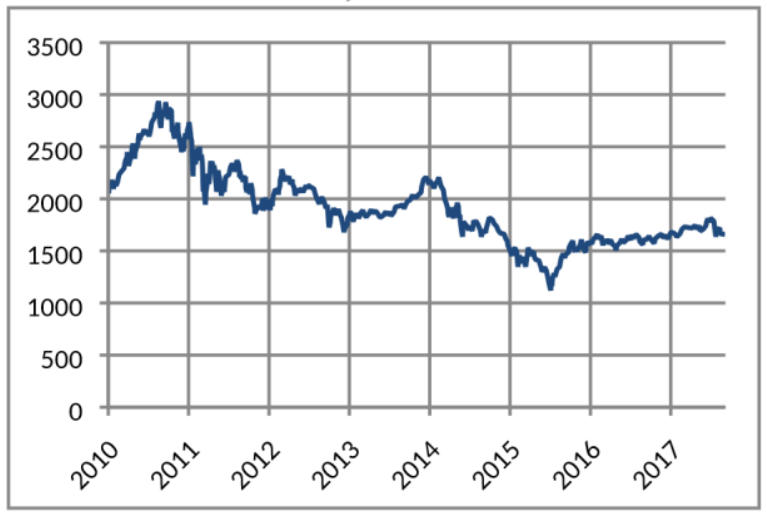

g) DJICA

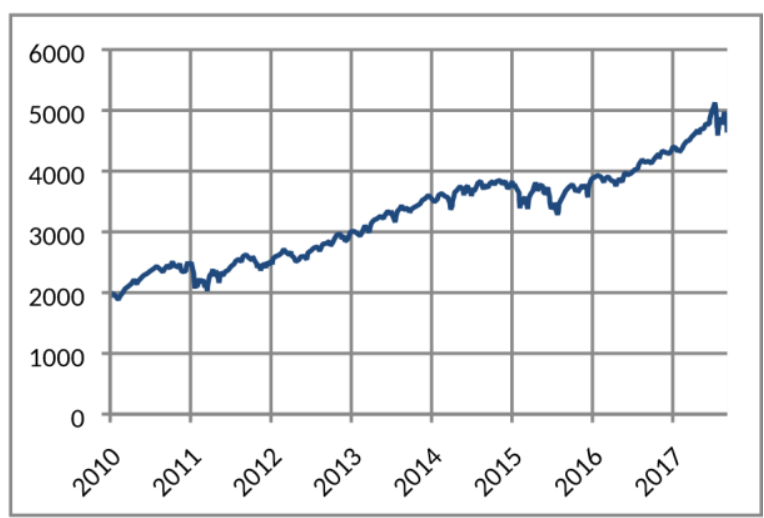

b) IMUS

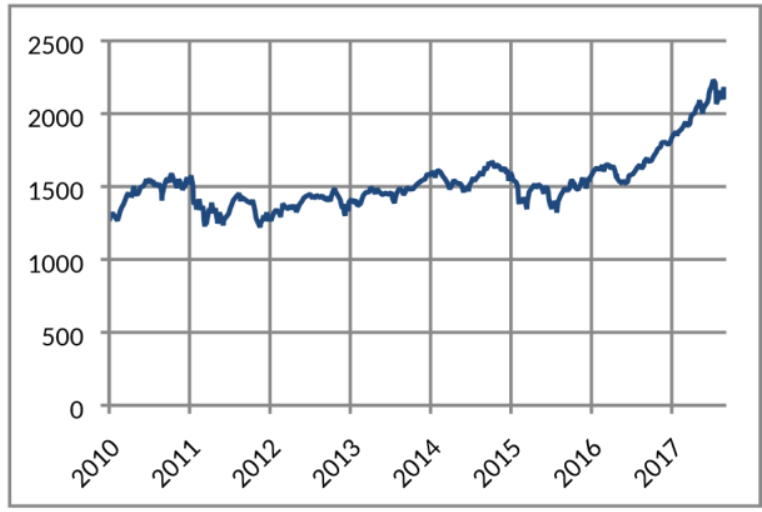

d) DJIAP

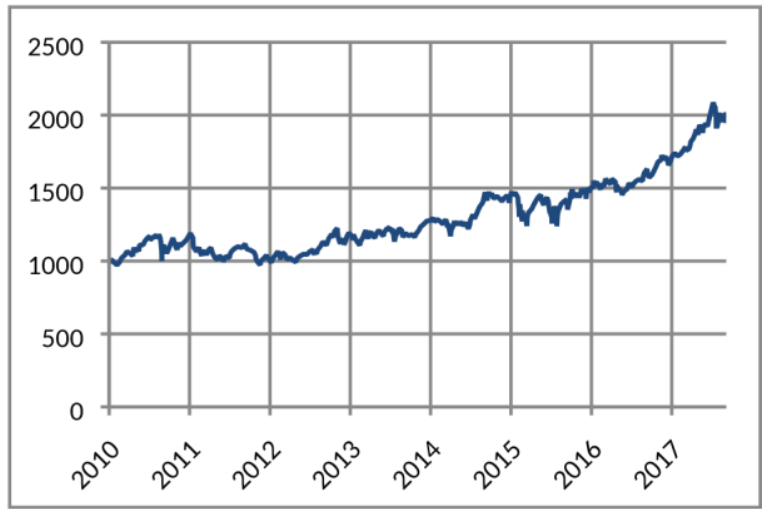

f) DJIJP

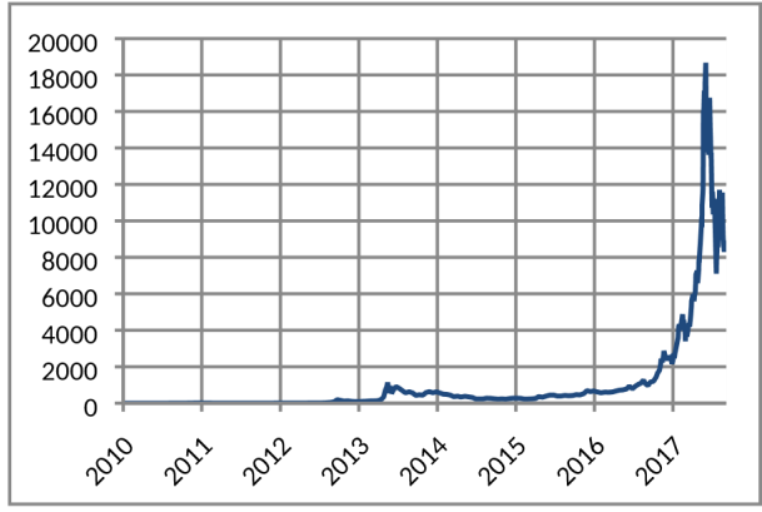

h) BTC 
Figure 1. Price Dynamics of Islamic indices and Bitcoin

\subsection{Preliminary analysis}

Table 1 provides descriptive statistics, unit root tests, Ljung-Box results and the ARCHLM test of the daily returns. As shown in Table 1, Bitcoin (BTC) earns highest average daily returns but with high associated volatility (i.e. standard deviation), indicating risk-return trade off. Most of returns have negative skewness and high kurtosis coefficients, indicating that the probability distributions of the futures returns are skewed and leptokurtic. These normality results are supported by Jarque-Bera (J-B) statistics which rejects the normality. Using the conventional ADF and PP unit root statistics tests and the stationarity property under the null using the KPSS test, the results indicate that all return series are stationary. Further, we also check the presence of serial correlation in the residuals and squared residuals up to the $20^{\text {th }}$ lag value, respectively, as well as the ARCH effect in the return series by applying the Ljung-Box and ARCH LM tests. The results highlight the presence of both, serial correlation and the ARCH effect in all cases. Therefore, the estimation of a GARCH model is appropriate for modeling some stylized facts, such as fat-tails, clustering volatility, and persistence, for Bitcoin and Islamic equity returns. Results for unconditional correlation of Bitcoin with Islamic indices show lower or even negative correlations, implying the presence of portfolio diversification benefits for investors. This linear correlation result provides a preliminary picture of the relationship between Bitcoin and Islamic equity markets and therefore to get more detailed insights of underlying relationship between two asset classes, we apply fractionally integrated GARCH framework.

Table 1. Descriptive statistics for seven Islamic indexes and Bitcoin returns 


\begin{tabular}{lllllllll}
\hline Statistics & DJIM & IMUS & DJIEU & DJIAP & DJIUK & DJIJP & DJICA & BTC \\
\hline Minimum & -0.0529 & -0.0641 & -0.0648 & -0.0468 & -0.1003 & -0.0684 & -0.0605 & -0.6009 \\
Maximum & 0.0375 & 0.0459 & 0.0526 & 0.0402 & 0.0554 & 0.0676 & 0.0629 & 0.5170 \\
Range & 0.0904 & 0.1100 & 0.1174 & 0.0870 & 0.1557 & 0.1359 & 0.1234 & 1.1180 \\
Mean & 0.0003 & 0.0004 & 0.0002 & 0.0003 & 0.0001 & 0.0003 & -0.0001 & 0.0058 \\
Std. dev. & 0.0079 & 0.0091 & 0.0110 & 0.0085 & 0.0119 & 0.0113 & 0.0126 & 0.0686 \\
Skewness & -0.5924 & -0.4875 & -0.3624 & -0.4530 & -0.5314 & -0.2425 & -0.2518 & -0.3354 \\
Kurtosis & 4.9494 & 4.6851 & 3.6403 & 2.8796 & 5.3163 & 3.7911 & 2.3812 & 13.639 \\
J-B stats. & $2162.6^{* * *}$ & $1912.2^{* * *}$ & $1150.4^{* * *}$ & $760.92^{* * *}$ & $2454.3^{* * *}$ & $1219.7^{* * *}$ & $494.65^{* * *}$ & $155711^{* * *}$ \\
ADF & $-38.26^{* * * *}$ & $-45.80^{* * *}$ & $-44.13^{* * *}$ & $-41.50^{* * *}$ & $-42.93^{* * *}$ & $-52.96^{* * *}$ & $-42.26^{* * *}$ & $-19.45^{* * *}$ \\
PP & $-37.79^{* * * *}$ & $-46.45^{* * *}$ & $-44.90^{* * * *}$ & $-41.40^{* * *}$ & $-43.95^{* * *}$ & $-55.60^{* * *}$ & $-42.21^{* * * *}$ & $-45.46^{* * *}$ \\
KPSS & 0.045 & 0.069 & 0.062 & 0.099 & 0.072 & 0.098 & 0.065 & 0.259 \\
Q(20) & $78.08^{* * *}$ & $39.92^{* * *}$ & 24.778 & $43.53^{* * *}$ & $34.84^{* * *}$ & $75.50^{* * *}$ & $39.06^{* * *}$ & $76.63^{* * *}$ \\
Q ${ }^{2}(20)$ & $914.2^{* * *}$ & $1309 .^{* * *}$ & $943.2^{* * *}$ & $681.8^{* * *}$ & $620.8^{* * *}$ & $505.2^{* * *}$ & $740.4^{* * *}$ & $528.1^{* * *}$ \\
ARCH(20) & $18.15^{* * *}$ & $28.75^{* * *}$ & $15.64^{* * *}$ & $12.64^{* * *}$ & $13.16^{* * *}$ & $19.91^{* * *}$ & $14.14^{* * *}$ & $17.35^{* * *}$ \\
\hline Unconditional & & & & & & & & \\
Correlation & $0.0704^{* * *}$ & $0.1389^{* * * *}$ & $0.1359^{* * *}$ & $0.0704^{* * *}$ & $0.0834^{* * *}$ & $-0.0121^{* * * *}$ & $0.1389^{* * *}$ & $0.0372^{* * *}$ \\
BTC & & & & & & & & \\
\hline Nor Q(20) & & & & & & &
\end{tabular}

Notes: $\mathrm{Q}(20)$ and $\mathrm{Q}^{2}(20)$ refer to the empirical statistics of Ljung-Box test for autocorrelation of returns and squared returns series, respectively. ADF, PP and KPSS are empirical statistics of the Augmented Dickey-Fuller (1979), and the Phillips-Perron (1988) unit root tests, and the Kwiatkowski et al. (1992) stationarity test, respectively. The ARCH LM (20) test of Engle (1982) checks the presence of the ARCH effects. J-B stands of the Jarque-Bera test of normality. ${ }^{* * *}$ denotes the rejection of the null hypotheses of normality, no autocorrelation, unit root, stationarity, and conditional homoscedasticity at the $1 \%$ significance level.

\section{Empirical results}

\subsection{Estimating marginal models}

Table 2 presents results for ARFIMA-FIGARCH models to investigate the long memory behavior of our sampled Islamic and Bitcoin indices. Panel A presents result for mean equation whereas Panel B gives coefficient of variance equation for each index. In order to select the best marginal model which is identified by the lowest AIC values, we use lag coefficient up to second order. We witness significant coefficients in mean equation for all series except DJICA at 1 percent significance level. These results highlight that for almost all series, past return values are reflected in current returns. Coefficients of fractional parameters also exhibit significance in most of the 
series thought few return parameters remain insignificant. Except DJIM, all series have positive coefficient values suggesting mean persistence behavior for most of the series. We use up to 2 lags for highlighting autoregressive and moving average behavior by each series. Almost all series (except DJIJP) exhibit autoregressive behavior however only at second lag value. For moving average model, again we witness significant results (except DJIM) at second lag values highlighting the importance or stochastic process in fractionally integrated model. Variance series results are different from mean equation results since all coefficients are insignificant suggesting no significant role of lagged variance values. However, we witness mean persistence behavior for all series suggesting persistent volatile behavior. DJIAP has the highest coefficient value for mean persistence compared to remaining Islamic as well as Bitcoin index. ARCH effect in the variance equation of ARFIMA model is evident for all series except Bitcoin however in its generalized form, we do not report significance up to 2 lags.

We provide evidence of asymmetry and fat tails in the error terms of all series. The presence of asymmetry together with degree of freedom under Student's $t$ distribution highlight the presence of fat tails, and therefore, the potential of dependence in the tails of joint distribution. To further validate our fractional integrated model, we use diagnostic tests, namely ARCH and Ljung-Box tests. We find no evidence of ARCH effect in the residuals of our model. Similarly, statistics for Ljung-Box test highlight no significant results of residuals and squared standardized residuals, thereby implying no presence of serial correlation.

Table 2. Marginal ARFIMA-FIGARCH model estimates 


\begin{tabular}{|c|c|c|c|c|c|c|c|c|}
\hline Statistics & DJIM & IMUS & DJIEU & DJIAP & DJIUK & DJIJP & DJICA & BTC \\
\hline \multicolumn{9}{|c|}{ Panel A: Mean equation } \\
\hline $\operatorname{Cst}(\mathrm{M})$ & $\begin{array}{l}0.0005^{* * *} \\
(0.0000)\end{array}$ & $\begin{array}{l}0.0007^{\text {*** }} \\
(0.0001)\end{array}$ & $\begin{array}{l}0.0004^{* *} \\
(0.0002)\end{array}$ & $\begin{array}{l}0.0006^{* * *} \\
(0.0002)\end{array}$ & $\begin{array}{l}0.0003^{* * *} \\
(0.0001)\end{array}$ & $\begin{array}{l}0.0007^{* * *} \\
(0.0002)\end{array}$ & $\begin{array}{l}0.0001^{* * *} \\
(0.0003)\end{array}$ & $\begin{array}{l}0.0025^{* *} \\
(0.0010)\end{array}$ \\
\hline d-Arfima & $\begin{array}{l}- \\
0.1301^{* * *} \\
(0.0405)\end{array}$ & $\begin{array}{l}0.0212 \\
(0.0402)\end{array}$ & $\begin{array}{l}0.0067 \\
(0.0536)\end{array}$ & $\begin{array}{l}0.0934^{* *} \\
(0.0499)\end{array}$ & $\begin{array}{l}0.0002 \\
(0.0265)\end{array}$ & $\begin{array}{l}0.0155 \\
(0.1294)\end{array}$ & $\begin{array}{l}0.1290^{* *} \\
(0.0596)\end{array}$ & $\begin{array}{l}0.0191 \\
(0.0476)\end{array}$ \\
\hline $\operatorname{AR}(1)$ & $\begin{array}{l}- \\
0.4099^{* * *} \\
(0.1892)\end{array}$ & $\begin{array}{l}0.1716 \\
(0.1172)\end{array}$ & $\begin{array}{l}-0.1311 \\
(0.1263)\end{array}$ & $\begin{array}{l}0.0264 \\
(0.1071)\end{array}$ & $\begin{array}{l}0.0162 \\
(0.0275)\end{array}$ & $\begin{array}{l}0.7107^{* * *} \\
(0.2437)\end{array}$ & $\begin{array}{l}0.0876 \\
(0.1016)\end{array}$ & $\begin{array}{l}-1.7561^{\text {** }} \\
(0.0966)\end{array}$ \\
\hline $\operatorname{AR}(2)$ & $\begin{array}{l}0.2092^{* *} \\
(0.1017)\end{array}$ & $\begin{array}{l}0.6660^{\text {*** }} \\
0.1181\end{array}$ & $\begin{array}{l}0.7834^{* * *} \\
(0.1144)\end{array}$ & $\begin{array}{l}0.7384^{* * *} \\
(0.0886)\end{array}$ & $\begin{array}{l}0.9242^{* * *} \\
(0.0313)\end{array}$ & $\begin{array}{l}0.0673 \\
(0.1406)\end{array}$ & $\begin{array}{l}0.6236^{* * *} \\
(0.0876)\end{array}$ & $\begin{array}{l}- \\
0.7934^{* * *} \\
(0.0822)\end{array}$ \\
\hline $\operatorname{MA}(1)$ & $\begin{array}{l}0.6407^{* * *} \\
(0.1820)\end{array}$ & $\begin{array}{l}-0.2340^{* *} \\
0.1256\end{array}$ & $\begin{array}{l}0.1045 \\
(0.1160)\end{array}$ & $\begin{array}{l}-0.0543 \\
(0.0801)\end{array}$ & $\begin{array}{l}-0.0190 \\
(0.0278)\end{array}$ & $\begin{array}{l}- \\
0.8897^{* * *} \\
(0.3070)\end{array}$ & $\begin{array}{l}-0.1810 \\
(0.1026)\end{array}$ & $\begin{array}{l}-1.7860^{\text {*** }} \\
(0.0886)\end{array}$ \\
\hline $\mathrm{MA}(2)$ & $\begin{array}{l}-0.0498 \\
(0.0853)\end{array}$ & $\begin{array}{l}- \\
0.6677^{\text {*** }} \\
(0.1240)\end{array}$ & $\begin{array}{l}-0.8115 \\
(0.1026)\end{array}$ & $\begin{array}{l}- \\
0.7896^{* * *} \\
(0.0727)\end{array}$ & $\begin{array}{l}- \\
0.9476^{* * *} \\
(0.0306)\end{array}$ & $\begin{array}{l}0.0321^{\text {*** }} \\
(0.1921)\end{array}$ & $\begin{array}{l}- \\
0.6656^{* * *} \\
(0.0897)\end{array}$ & $\begin{array}{l}0.8291^{* * *} \\
(0.0767)\end{array}$ \\
\hline \multicolumn{9}{|c|}{ Panel B: Variance equation } \\
\hline $\operatorname{Cst}(\mathrm{V})$ & $\begin{array}{l}0.0487 \\
(0.0680)\end{array}$ & $\begin{array}{l}4.7198 \\
9.5456\end{array}$ & $\begin{array}{l}0.0051 \\
(0.0281)\end{array}$ & $\begin{array}{l}0.1092 \\
(0.0834)\end{array}$ & $\begin{array}{l}0.0361 \\
(0.0276)\end{array}$ & $\begin{array}{l}0.0147 \\
(0.0149)\end{array}$ & $\begin{array}{l}0.0190 \\
(0.0138)\end{array}$ & $\begin{array}{l}0.3283 \\
(0.2701)\end{array}$ \\
\hline d-Figarch & $\begin{array}{l}0.7111^{* * *} \\
(0.2360)\end{array}$ & $\begin{array}{l}0.4005^{* * *} \\
0.0856\end{array}$ & $\begin{array}{l}0.4726^{* *} \\
(0.2608)\end{array}$ & $\begin{array}{l}0.8691^{* * *} \\
(0.1380)\end{array}$ & $\begin{array}{l}0.4226^{* * *} \\
(0.0926)\end{array}$ & $\begin{array}{l}0.3787^{* *} \\
(0.1733)\end{array}$ & $\begin{array}{l}0.4898^{* * *} \\
(0.0709)\end{array}$ & $\begin{array}{l}0.6650^{* * *} \\
(0.0857)\end{array}$ \\
\hline $\mathrm{ARCH}(\mathrm{Phil1})$ & $\begin{array}{l}0.9208^{* * *} \\
(0.0473)\end{array}$ & $\begin{array}{l}0.0000 \\
1.9124\end{array}$ & $\begin{array}{l}0.7811^{\text {*** }} \\
(0.8118)\end{array}$ & $\begin{array}{l}0.8016^{* * *} \\
(0.0931)\end{array}$ & $\begin{array}{l}0.1976 \\
(0.3343)\end{array}$ & $\begin{array}{l}0.7804^{* * *} \\
(0.1002)\end{array}$ & $\begin{array}{l}0.3185^{\text {*** }} \\
(0.1613)\end{array}$ & $\begin{array}{l}0.2525 \\
(0.2197)\end{array}$ \\
\hline GARCH(Beta1) & $\begin{array}{l}1.5757^{* * *} \\
(0.2229)\end{array}$ & $\begin{array}{l}0.2581 \\
1.9547\end{array}$ & $\begin{array}{l}1.2012 \\
(1.0613)\end{array}$ & $\begin{array}{l}1.6029^{* * * *} \\
(0.1782)\end{array}$ & $\begin{array}{l}0.5107 \\
(0.3507)\end{array}$ & $\begin{array}{l}0.9955^{\text {*** }} \\
(0.1780)\end{array}$ & $\begin{array}{l}0.7425^{* * *} \\
(0.1840)\end{array}$ & $\begin{array}{l}0.7047^{* * *} \\
(0.2254)\end{array}$ \\
\hline GARCH(Beta2) & $\begin{array}{l}- \\
0.5904^{* * *} \\
(0.2105)\end{array}$ & $\begin{array}{l}-0.0000 \\
(0.4801)\end{array}$ & $\begin{array}{l}-0.3031 \\
(0.5703)\end{array}$ & $\begin{array}{l}- \\
0.6245^{* * *} \\
(0.1620)\end{array}$ & $\begin{array}{l}0.0013 \\
(0.1109)\end{array}$ & $\begin{array}{l}-0.1212 \\
(0.1044)\end{array}$ & $\begin{array}{l}-0.0469 \\
(0.0823)\end{array}$ & $\begin{array}{l}0.0087 \\
(0.1310)\end{array}$ \\
\hline Asymmetry & $\begin{array}{l}- \\
0.0881^{* * *} \\
(0.0296)\end{array}$ & $\begin{array}{l}- \\
0.5547^{* * *} \\
(0.0546)\end{array}$ & $\begin{array}{l}- \\
0.3443^{* * *} \\
(0.0546)\end{array}$ & $\begin{array}{l}- \\
0.5034^{* * *} \\
(0.0546)\end{array}$ & $\begin{array}{l}- \\
0.3448^{* * *} \\
(0.0584)\end{array}$ & $\begin{array}{l}- \\
0.4121^{* * *} \\
(0.0546)\end{array}$ & $\begin{array}{l}- \\
0.4024^{* * *} \\
(0.0546)\end{array}$ & $\begin{array}{l}-0.0590 \\
(0.0546)\end{array}$ \\
\hline Tail & $\begin{array}{l}5.2409^{* * * *} \\
(0.6501)\end{array}$ & $\begin{array}{l}1.6833^{* * *} \\
(0.1092)\end{array}$ & $\begin{array}{l}1.7175^{* * * *} \\
(0.1092)\end{array}$ & $\begin{array}{l}1.4697^{* * * *} \\
0.109304\end{array}$ & $\begin{array}{l}1.6709^{* * * *} \\
0.109302\end{array}$ & $\begin{array}{l}1.8206^{* * *} \\
0.109299\end{array}$ & $\begin{array}{l}1.0884^{* * * *} \\
0.1093\end{array}$ & $\begin{array}{l}6.2233^{* * *} \\
0.1093\end{array}$ \\
\hline
\end{tabular}

Panel C: Diagnostics

\begin{tabular}{lllllllll}
\hline LL & 7226.46 & 6872.769 & 6448.614 & 6903.847 & 6307.956 & 6324.156 & 6136.310 & 3131.430 \\
AIC & -7.1991 & 6.8481 & -6.4248 & -6.8791 & -6.2844 & -6.3006 & -6.1131 & -3.1142 \\
ARCH(20) & 0.4704 & 0.3443 & 0.6619 & 1.1577 & 0.4111 & 0.7483 & 1.1134 & 1.3788 \\
& {$[0.9774]$} & {$[0.9970]$} & {$[0.8662]$} & {$[0.2828]$} & {$[0.9901]$} & {$[0.7776]$} & {$[0.3275]$} & {$[0.1215]$} \\
Q(20) & 16.6294 & 15.8729 & 13.5363 & 12.4671 & 13.7155 & 8.5973 & 10.4484 & 61.7177 \\
& {$[0.4099]$} & {$[0.4619]$} & {$[0.6312]$} & {$[0.7113]$} & {$[0.6199]$} & {$[0.9291]$} & {$[0.8422]$} & {$[0.0000]$} \\
$\mathrm{Q}^{2}(20)$ & 7.8054 & 6.5556 & 10.3189 & 22.5272 & 8.0281 & 14.1981 & 21.2831 & 25.7236 \\
& {$[0.9705]$} & {$[0.9886]$} & {$[0.8897]$} & {$[0.1653]$} & {$[0.9659]$} & {$[0.6530]$} & {$[0.2139]$} & {$[0.0797]$}
\end{tabular}


Notes: Cst(M) and Cst(V) represent parameters for mean and variance equations, respectively. d-Arfima and d-Figarch highlight fractional differencing parameters for mean and variance equations, respectively. Above table present ML results with respective

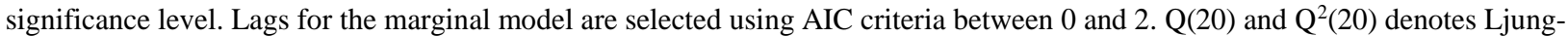
Box test statistics for serial correlation whereas $\mathrm{ARCH}(20)$ represents autoregressive conditional heteroscedasticity, tested through Engel (1982) at 20 lags. ${ }^{*},{ }^{* *},{ }^{* * *}$ denotes significance at the 10,5 and $1 \%$ levels, respectively.

Figure 2 presents the time-varying conditional volatilities estimated from the ARFIMAFIGARCH model under the skewed Student's $t$ distribution. We can see that all Islamic indices exhibit volatile behavior across the sample period however the magnitude of this turbulence is not high. This volatility suggests that though Islamic assets are asset backed and are considered as safe investments, they may require effective diversification for reducing any unsystematic risk. Bitcoin however, exhibit high swings of volatility contrary to Islamic indices which reflects the need of an asset class with consistent returns together in a portfolio.

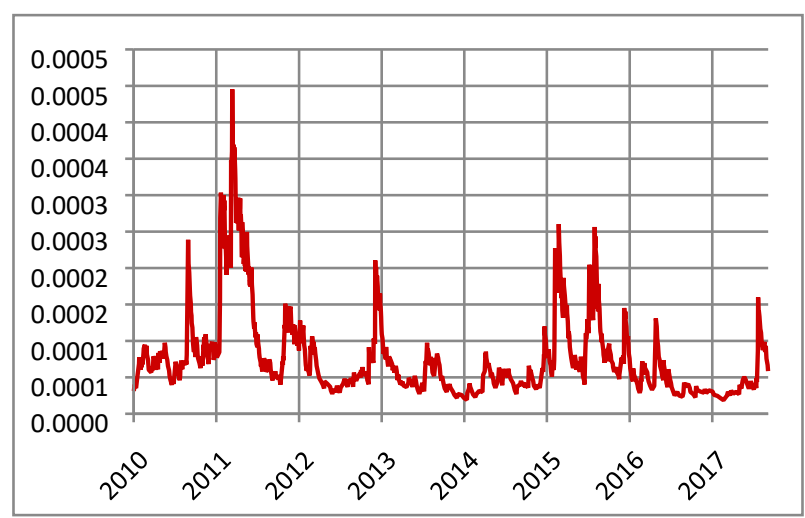

a) DJIM

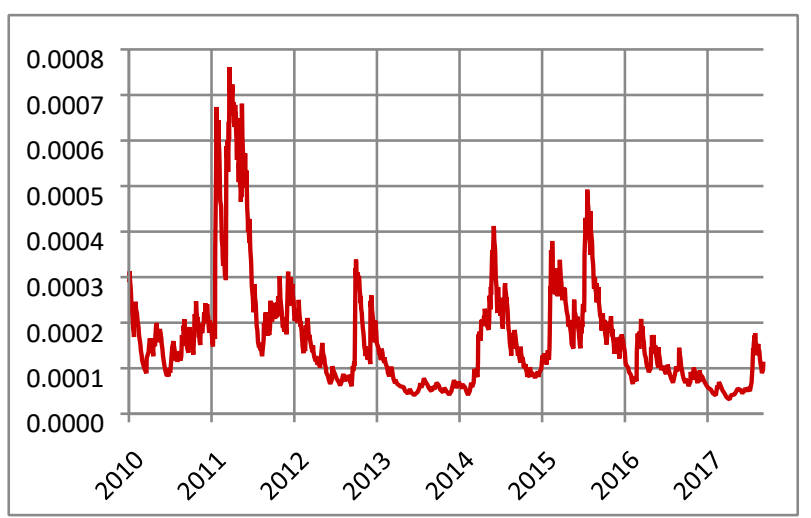

b) IMUS 


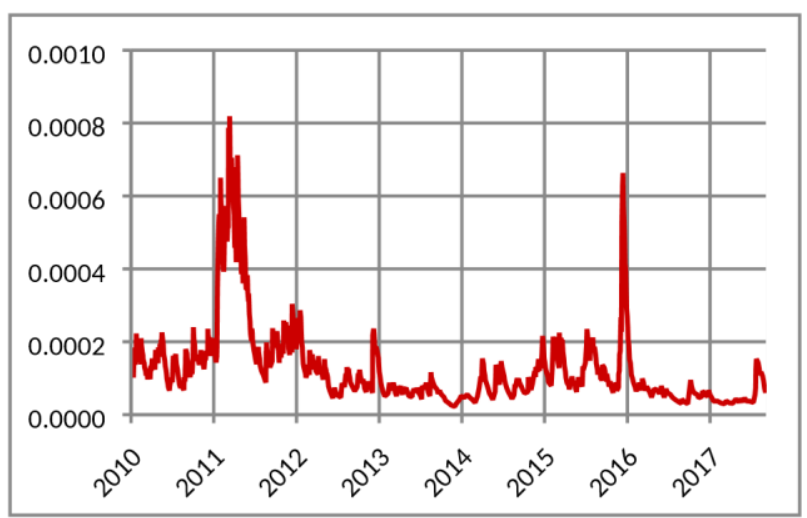

c) DJIEU

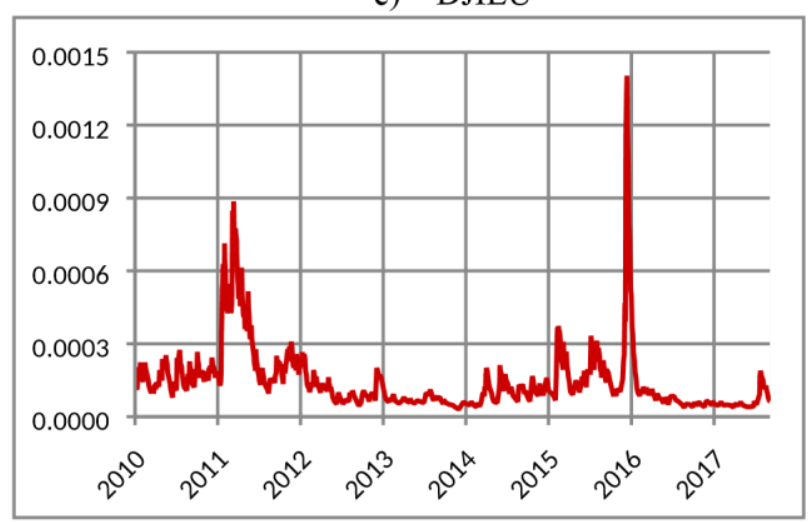

e) DJIUK

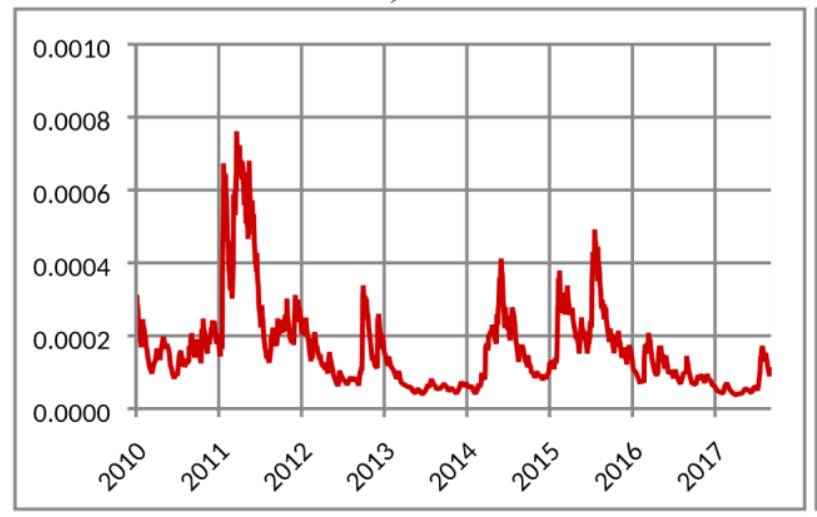

g) DJICA

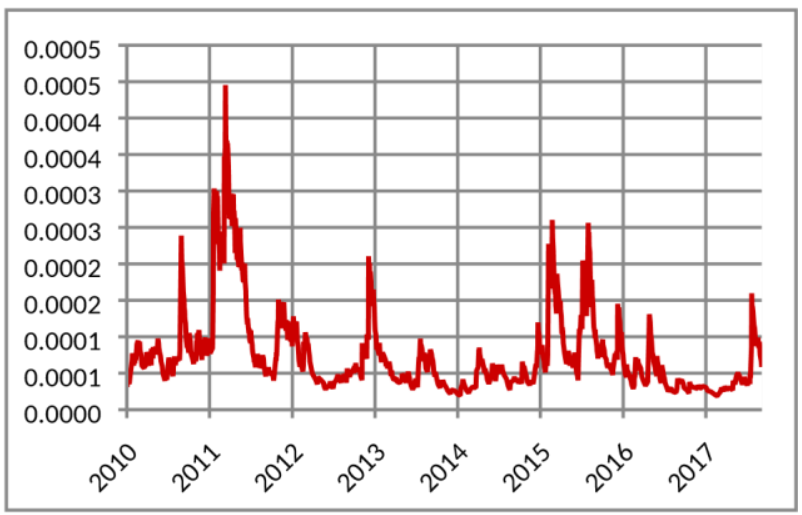

d) DJIAP

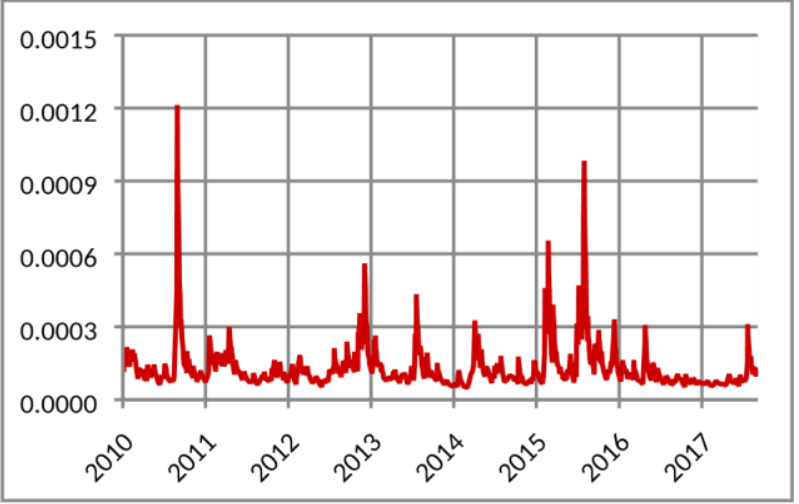

f) DJIJP

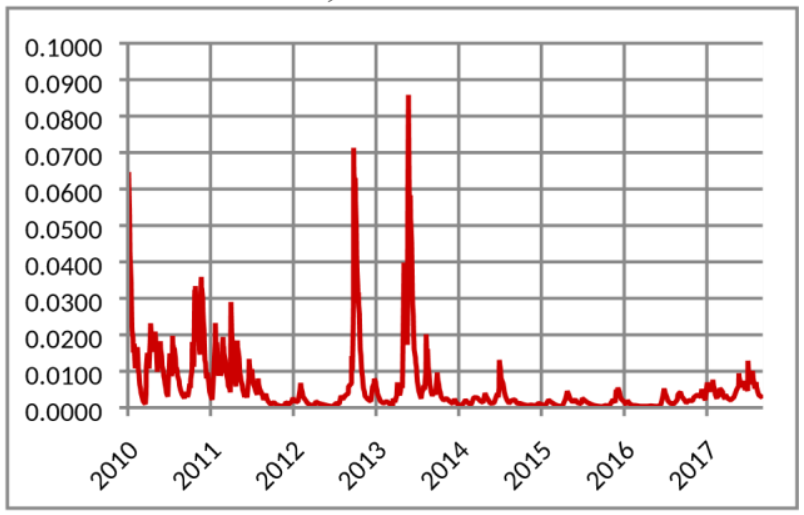

h) BTC

Figure 2. Conditional volatilities of Islamic indices and Bitcoin returns

\subsection{Estimating the copula models}

Table 3 shows results of dependence structure using time invariant and time varying copulas between Islamic-Bitcoin pairs. To select the best fitted copulas based on small AIC values 
after adjusting for small sample bias, we apply a range of copulas from time variant and time invariant framework. Results in Table 3 highlight time-invariant copulas as best fitted for the pair between Bitcoin and DJIM, IMUS, DJIEU and DJIAP pairs. For remaining pair, we witness timevarying copulas as best fitted model, i.e. rotated Gumbel for Bitcoin-DJIUK, rotated clayton for Bitcoin-DJIJP and Clayton copula for Bitcoin-DJICA pairs, however with significant temporal variations. Among all Bitcoin-Islamic pairs, Bitcoin and DJIM, IMUS, DJIEU, DJIAP pairs demonstrate time invariant behavior under bivariate Student $t$ copulas. These results suggest that for these asset pairs, the parameters of underlying dependence structure do not change over time. Furthermore, the presence of Student's $t$ copula is characterized by symmetrical tail dependence suggesting a linear and direct relationship between returns under bearish market conditions. The results depict the potential of Bitcoin and Islamic indices to induce change towards other markets under extreme downward return co-movements.

For Bitcoin-DJIUK pair, extreme lower tail dependence is characterized by the best fitted rotated Gumbel copula suggesting that both equity returns co-move under extreme downward returns. Such relationship may not be recommended for portfolio formulation based on these two asset classes only. Bitcoin-DJIJP pair is the best fitted under clayton copula implying upper tail dependence between two asset classes. These results suggest optimal results for investors since both assets seems to co-move under bullish market conditions. Finally, Bitcoin-DJICA is best fitted as Clayton copula under time varying framework thereby exhibiting upper tail independence and lower tail dependence. This situation can induce spillover effect in case of extreme downward movements between Bitcoin and DJICA equity markets. However, under bullish market conditions, we do not witness any significant co-movement of returns between these two asset classes.

Table 3. The estimated results of copula dependence structure 


\begin{tabular}{|c|c|c|c|c|c|c|c|}
\hline & DJIM & IMUS & DJIEU & DJIAP & DJIUK & DJIJP & DJICA \\
\hline \multicolumn{8}{|c|}{ a) Time-invariant Copulas } \\
\hline $\begin{array}{l}\text { 1. Gaussian } \\
\text { B }\end{array}$ & $\begin{array}{l}0.0290^{* * *} \\
(0.0223)\end{array}$ & $\begin{array}{l}0.0351^{\text {*** }} \\
(0.0223)\end{array}$ & $\begin{array}{l}0.0463^{\text {*** }} \\
(0.0223)\end{array}$ & $\begin{array}{l}-0.0255^{\text {*** }} \\
(0.0223)\end{array}$ & $\begin{array}{l}0.0411^{* * *} \\
(0.0223)\end{array}$ & $\begin{array}{l}-0.0123^{* * * *} \\
(0.0223)\end{array}$ & $\begin{array}{l}0.0177^{* * *} \\
(0.0223)\end{array}$ \\
\hline $\begin{array}{l}\text { AIC } \\
\text { LL }\end{array}$ & $\begin{array}{l}-1.6899 \\
-0.8454\end{array}$ & $\begin{array}{l}-2.4656 \\
-1.2333\end{array}$ & $\begin{array}{l}-4.2912 \\
-2.1461\end{array}$ & $\begin{array}{l}-1.3038 \\
-0.6524\end{array}$ & $\begin{array}{l}-3.3839 \\
-1.6924\end{array}$ & $\begin{array}{l}-0.3010 \\
-0.1510\end{array}$ & $\begin{array}{l}-0.6286 \\
-0.3148\end{array}$ \\
\hline $\begin{array}{l}\text { 2. Clayton's } \\
\partial\end{array}$ & $\begin{array}{l}0.0561^{* * *} \\
(0.0240)\end{array}$ & $\begin{array}{l}0.0569^{* * *} \\
(0.0242)\end{array}$ & $\begin{array}{l}0.0702^{* * *} \\
(0.0250)\end{array}$ & $\begin{array}{l}0.0063^{* * *} \\
(0.0218)\end{array}$ & $\begin{array}{l}0.0686^{* * *} \\
(0.0249)\end{array}$ & $\begin{array}{l}0.0001 \\
(0.0353)\end{array}$ & $\begin{array}{l}0.0591^{\text {**** }} \\
(0.0240)\end{array}$ \\
\hline $\begin{array}{l}\text { AIC } \\
\text { LL }\end{array}$ & $\begin{array}{l}-6.3124 \\
-3.1567\end{array}$ & $\begin{array}{l}-6.4259 \\
-3.2134\end{array}$ & $\begin{array}{l}-9.2767 \\
-4.6389\end{array}$ & $\begin{array}{l}-0.0831 \\
-0.0420\end{array}$ & $\begin{array}{l}-8.9330 \\
-4.4670\end{array}$ & $\begin{array}{l}0.0060 \\
0.0025\end{array}$ & $\begin{array}{l}-7.0642 \\
-3.5326\end{array}$ \\
\hline $\begin{array}{l}\text { 3. Rotated } \\
\text { Clayt }\end{array}$ & $\begin{array}{l}\text { on } \\
0.0269^{* * * *}\end{array}$ & & & & & & \\
\hline$\Delta$ & $(0.0231)$ & $\begin{array}{l}0.0304^{\text {*** }} \\
(0.0237)\end{array}$ & $\begin{array}{l}0.0463^{\text {*** }} \\
(0.0242)\end{array}$ & $\begin{array}{l}0.0001 \\
(0.0358)\end{array}$ & $\begin{array}{l}0.0363^{\text {*** }} \\
(0.0241)\end{array}$ & $\begin{array}{l}0.0013^{\text {*** }} \\
(0.0224)\end{array}$ & $\begin{array}{l}0.0001 \\
(0.0352)\end{array}$ \\
\hline AIC & -1.4655 & -1.7806 & -4.0966 & 0.0103 & -2.4726 & -0.0027 & 0.0038 \\
\hline LL & -0.7333 & -0.8908 & -2.0488 & 0.0046 & -1.2368 & -0.0018 & 0.0014 \\
\hline $\begin{array}{l}\text { 4. Plackett } \\
\prod\end{array}$ & $\begin{array}{l}1.0443^{* * *} \\
(0.0718)\end{array}$ & $\begin{array}{l}1.0719^{* * * *} \\
(0.0734)\end{array}$ & $\begin{array}{l}1.1106^{* * *} \\
(0.0778)\end{array}$ & $\begin{array}{l}0.9154^{* * *} \\
(0.0635)\end{array}$ & $\begin{array}{l}1.0913^{* * *} \\
(0.0756)\end{array}$ & $\begin{array}{l}0.9444^{* * *} \\
(0.0640)\end{array}$ & $\begin{array}{l}1.0020^{* * *} \\
(0.0674)\end{array}$ \\
\hline AIC & -0.3981 & -1.0393 & -2.2861 & -1.6487 & -1.6124 & -0.7186 & 0.0001 \\
\hline LL & -0.1996 & -0.5201 & -1.1436 & -0.8248 & -0.8067 & -0.3598 & 0.0004 \\
\hline $\begin{array}{l}\text { 5. Frank } \\
\mathrm{T}\end{array}$ & $\begin{array}{l}0.0838^{* * * *} \\
(0.1355)\end{array}$ & $\begin{array}{l}0.1357^{* * * *} \\
(0.1353)\end{array}$ & $\begin{array}{l}0.2003^{* * *} \\
(0.1364)\end{array}$ & $\begin{array}{l}0.0001 \\
(0.1354)\end{array}$ & $\begin{array}{l}0.1681^{* * *} \\
(0.1360)\end{array}$ & $\begin{array}{l}0.0001 \\
(0.1346)\end{array}$ & $\begin{array}{l}0.0038 \\
(0.1386)\end{array}$ \\
\hline AIC & -0.3868 & -1.0167 & -2.1793 & 0.0029 & -1.5546 & 0.0022 & 0.0001 \\
\hline LL & -0.1939 & -0.5088 & -1.0901 & 0.0010 & -0.7778 & 0.0006 & 0.0004 \\
\hline $\begin{array}{l}\text { 6. Gumbel } \\
\varnothing\end{array}$ & $\begin{array}{l}1.1000^{* * *} \\
(0.0277)\end{array}$ & $\begin{array}{l}1.1000^{* * *} \\
(0.0277)\end{array}$ & $\begin{array}{l}1.1000^{* * *} \\
(0.0276)\end{array}$ & $\begin{array}{l}1.1000^{* * * *} \\
(0.0283)\end{array}$ & $\begin{array}{l}1.1000^{* * *} \\
(0.0276)\end{array}$ & $\begin{array}{l}1.1000^{* * *} \\
(0.0281)\end{array}$ & $\begin{array}{l}1.1000^{\text {**** }} \\
(0.0280)\end{array}$ \\
\hline $\begin{array}{l}\text { AIC } \\
\text { LL }\end{array}$ & $\begin{array}{l}28.5092 \\
14.2541\end{array}$ & $\begin{array}{l}26.8159 \\
13.4074\end{array}$ & $\begin{array}{l}18.1484 \\
9.0737\end{array}$ & $\begin{array}{l}58.1029 \\
29.0509\end{array}$ & $\begin{array}{l}21.6677 \\
10.8334\end{array}$ & $\begin{array}{l}52.8851 \\
26.4421\end{array}$ & $\begin{array}{l}44.9365 \\
22.4677\end{array}$ \\
\hline 7. Rotated C & bel & & & & & & \\
\hline$\gamma$ & $\begin{array}{l}1.1000^{\text {*** }} \\
(0.0275)\end{array}$ & $\begin{array}{l}1.1000^{\text {*** }} \\
(0.0275)\end{array}$ & $\begin{array}{l}1.1000^{\text {*** }} \\
(0.0274)\end{array}$ & $\begin{array}{l}1.1000^{* * *} \\
(0.0282)\end{array}$ & $\begin{array}{l}1.1000^{* * * *} \\
(0.0273)\end{array}$ & $\begin{array}{l}1.1000^{* * *} \\
(0.0282)\end{array}$ & $\begin{array}{l}1.1000^{* * *} \\
(0.0275)\end{array}$ \\
\hline AIC & 18.3304 & 16.9456 & 6.4953 & 49.6537 & 7.3596 & 55.2017 & 22.6668 \\
\hline LL & 9.1647 & 8.4723 & 3.4272 & 24.8263 & 3.6793 & 27.6003 & 11.3329 \\
\hline
\end{tabular}




\begin{tabular}{|c|c|c|c|c|c|c|c|}
\hline & DJIM & IMUS & DJIEU & DJIAP & DJIUK & DJIJP & DJICA \\
\hline \multicolumn{8}{|c|}{ 8. Student's $t$} \\
\hline \multirow[t]{2}{*}{$? ?$} & $0.0212^{* * *}$ & $0.0301^{* * *}$ & $0.0382^{* * *}$ & $-0.0274^{* * *}$ & $0.0351^{* * *}$ & $-0.0130^{* * * *}$ & $0.0128^{* * *}$ \\
\hline & $(0.0213)$ & $(0.0240)$ & $(0.0245)$ & $(0.0236)$ & $(0.0224)$ & $(0.0239)$ & $(0.0236)$ \\
\hline \multirow[t]{2}{*}{$\mathrm{T}$} & $11.887^{* * *}$ & $14.849^{* * *}$ & $9.4158^{* * *}$ & $14.085^{* * *}$ & 0.0059 & 48.756 & $23.026^{*}$ \\
\hline & $(3.3074)$ & $(5.4621)$ & $(2.4228)$ & $(5.0903)$ & $(2.6054)$ & $(54.504)$ & $(12.148)$ \\
\hline AIC & -14.2464 & -10.7725 & -22.6236 & -9.5737 & 10.1963 & -0.9771 & -4.2697 \\
\hline $\mathrm{LL}$ & -7.1242 & -5.3872 & -11.3128 & -4.7878 & -9.7575 & -0.4896 & -2.1359 \\
\hline \multicolumn{8}{|c|}{ 9. Symmetrized JC } \\
\hline \multirow[t]{2}{*}{$\mathrm{E}$} & 0.0000 & 0.0000 & 0.0000 & 0.0000 & 0.0000 & 0.0000 & 0.0000 \\
\hline & $(0.0000)$ & $(5828.1)$ & $(0.0015)$ & $(2.2955)$ & $(0.0000)$ & $(0.2481)$ & $(0.0041)$ \\
\hline \multirow[t]{2}{*}{ M } & $0.0018^{* * *}$ & 0.0011 & 0.0053 & 0.0000 & $0.0059^{* * *}$ & 0.0000 & 0.0019 \\
\hline & $(0.0207)$ & $(9459.3)$ & $(0.1594)$ & $(0.8813)$ & $(0.0064)$ & (1.1661) & (732.23) \\
\hline AIC & -6.7939 & -6.6597 & -10.5331 & 5.3805 & -9.8289 & 4.8033 & -5.3825 \\
\hline LL & -3.3980 & -3.3308 & -5.2676 & 2.6893 & -4.9155 & 2.4007 & -2.6922 \\
\hline
\end{tabular}

b) Time-varying (TVP) Copulas

\begin{tabular}{|c|c|c|c|c|c|c|c|}
\hline \multicolumn{8}{|c|}{ 1. TVP-Gaussian } \\
\hline $\mathrm{T}$ & $\begin{array}{c}0.0660^{* * *} \\
(0.0544)\end{array}$ & $\begin{array}{c}0.0807^{*} \\
(0.0690)\end{array}$ & $\begin{array}{c}0.0411^{* * * *} \\
(0.1131)\end{array}$ & $\begin{array}{l}-0.0857^{*} \\
(0.0499)\end{array}$ & $\begin{array}{c}0.0872 \\
(0.0621)\end{array}$ & $\begin{array}{l}-0.0323 \\
(0.0504)\end{array}$ & $\begin{array}{c}0.0643 \\
(0.0549)\end{array}$ \\
\hline A & $\begin{array}{l}-0.0133 \\
(0.0806)\end{array}$ & $\begin{array}{l}-0.0611 \\
(0.0877)\end{array}$ & $\begin{array}{c}0.0247 \\
(0.0673)\end{array}$ & $\begin{array}{l}-0.1672 \\
(0.1323)\end{array}$ & $\begin{array}{c}0.0173 \\
(0.0850)\end{array}$ & $\begin{array}{l}-0.1241 \\
(0.1564)\end{array}$ & $\begin{array}{l}-0.2034^{* *} \\
(0.1196)\end{array}$ \\
\hline B & $\begin{array}{l}-0.0203 \\
(1.0158)\end{array}$ & $\begin{array}{c}0.0440 \\
(1.2544)\end{array}$ & $\begin{array}{l}1.1220^{* *} \\
(2.3811)\end{array}$ & $\begin{array}{l}-1.1362 \\
(0.8405)\end{array}$ & $\begin{array}{l}-0.0092 \\
(0.9980)\end{array}$ & $\begin{array}{l}-0.7294 \\
(2.2159)\end{array}$ & $\begin{array}{l}-0.4324 \\
(0.9329)\end{array}$ \\
\hline AIC & -1.7329 & -3.0406 & -4.6933 & -2.9064 & -3.4389 & -1.1684 & -3.3405 \\
\hline LL & -0.8680 & -1.5218 & -2.3481 & -1.4547 & -1.7209 & -0.5857 & -1.6718 \\
\hline 2. TVP- & 's & & & & & & \\
\hline Clayton & $0.1254^{* * *}$ & & & & & & \\
\hline$\Psi_{0}$ & $(0.0010)$ & $\begin{array}{c}0.8319^{* * *} \\
(0.0444)\end{array}$ & $\begin{array}{c}0.5806^{* * *} \\
(0.1154)\end{array}$ & $\begin{array}{c}0.4595^{* * *} \\
(0.0478)\end{array}$ & $\begin{array}{c}-0.1591^{* * *} \\
(0.0264)\end{array}$ & $\begin{array}{c}0.0098 \\
(0.5397)\end{array}$ & $\begin{array}{c}0.3020^{* * *} \\
(0.0364)\end{array}$ \\
\hline$\Psi_{1}$ & $\begin{array}{c}-0.0393^{* * *} \\
(0.0040)\end{array}$ & $\begin{array}{c}-2.7588^{* * *} \\
(0.5953)\end{array}$ & $\begin{array}{c}-1.7725^{* * *} \\
(0.2888)\end{array}$ & $\begin{array}{l}1.2741^{* * *} \\
(0.3774)\end{array}$ & $\begin{array}{c}-1.5277^{* * *} \\
(0.1012)\end{array}$ & $\begin{array}{c}1.0130 \\
(1.6596)\end{array}$ & $\begin{array}{c}0.4842 \\
(0.5755)\end{array}$ \\
\hline$\Psi_{2}$ & $\begin{array}{c}0.3630^{* * *} \\
(0.0006)\end{array}$ & $\begin{array}{c}-1.1284^{* * *} \\
(0.1197)\end{array}$ & $\begin{array}{c}-0.4922^{* * *} \\
(0.2189)\end{array}$ & $\begin{array}{c}-1.5160^{* * *} \\
(0.1761)\end{array}$ & $\begin{array}{c}0.0036 \\
(0.0861)\end{array}$ & $\begin{array}{c}-0.0274 \\
(1.7611)\end{array}$ & $\begin{array}{c}-1.5371^{* * * *} \\
(0.2223)\end{array}$ \\
\hline AIC & -7.1499 & -8.5097 & -10.3503 & -3.5652 & -8.9409 & 0.0084 & -11.8561 \\
\hline LL & -3.5764 & -4.2563 & -5.1767 & -1.7841 & -4.4720 & 0.0027 & -5.9296 \\
\hline 3. TVP-I & Clayton & & & & & & \\
\hline $\mathrm{T}$ & $\begin{array}{c}0.3961^{* * *} \\
(0.1066)\end{array}$ & $\begin{array}{c}0.4286^{* * *} \\
(0.0010)\end{array}$ & $\begin{array}{l}0.2526^{* * * *} \\
(0.0001)\end{array}$ & $\begin{array}{l}0.4243^{* *} \\
(0.2265)\end{array}$ & $\begin{array}{l}-0.3052 \\
(0.2530)\end{array}$ & $\begin{array}{l}0.7384^{* * *} \\
(0.1757)\end{array}$ & $\begin{array}{l}-0.4773^{*} \\
(0.2979)\end{array}$ \\
\hline A & $-4.8356^{* * *}$ & $-4.7651^{* * * *}$ & $-3.7140^{* * * *}$ & $1.1589^{* *}$ & $1.0333^{*}$ & 0.4969 & -0.4605 \\
\hline
\end{tabular}




\begin{tabular}{|c|c|c|c|c|c|c|c|}
\hline $\mathrm{E}$ & $\begin{array}{l}0.0000 \\
(0.4711)\end{array}$ & $\begin{array}{l}0.0000 \\
(0.0803)\end{array}$ & $\begin{array}{l}0.0000 \\
(0.0000)\end{array}$ & $\begin{array}{l}0.0000 \\
\quad(0.6962)\end{array}$ & $\begin{array}{l}0.0000 \\
(0.9340)\end{array}$ & $\begin{array}{l}0.0000 \\
\quad(0.5275)\end{array}$ & $\begin{array}{l}0.0000 \\
(3.6598)\end{array}$ \\
\hline B & $\begin{array}{l}-0.0095 \\
(0.0564)\end{array}$ & $\begin{array}{c}-0.3903^{* * *} \\
(0.0012)\end{array}$ & $\begin{array}{c}0.0803^{\text {*** }} \\
(0.0000)\end{array}$ & $\begin{array}{c}-1.2050^{*} \\
(0.6563)\end{array}$ & $\begin{array}{c}0.1921 \\
(0.6666)\end{array}$ & $\begin{array}{c}-2.2385^{* * *} \\
(0.4659)\end{array}$ & $\begin{array}{c}1.3470^{*} \\
(0.7193)\end{array}$ \\
\hline AIC & -8.7106 & -7.4995 & -3.3763 & -0.7517 & -2.5521 & -8.0294 & -0.8734 \\
\hline LL & -4.3568 & -3.7513 & -1.6896 & -0.3774 & -1.2776 & -4.0162 & -0.4382 \\
\hline \multicolumn{8}{|c|}{ 4. TVP-Gumbel } \\
\hline $\mathrm{T}_{\mathrm{u}}$ & $\begin{array}{c}-3.1645^{\text {*** }} \\
(0.6495)\end{array}$ & $\begin{array}{c}1.2040 \\
(0.9406)\end{array}$ & $\begin{array}{l}-1.6257 \\
(1.0855)\end{array}$ & $\begin{array}{c}0.9835 \\
(0.6453)\end{array}$ & $\begin{array}{l}-0.7654 \\
(0.6076)\end{array}$ & $\begin{array}{c}1.2488 \\
(0.9245)\end{array}$ & $\begin{array}{l}1.4500^{* * *} \\
(0.5883)\end{array}$ \\
\hline$\alpha_{\mathrm{u}}$ & $\begin{array}{c}2.7269^{* * *} \\
(0.7816)\end{array}$ & $\begin{array}{l}-1.2051 \\
(1.0423)\end{array}$ & $\begin{array}{c}1.1037 \\
(1.1179)\end{array}$ & $\begin{array}{c}-1.3357^{* *} \\
(0.5211)\end{array}$ & $\begin{array}{c}0.5185 \\
(0.5674)\end{array}$ & $\begin{array}{l}-0.8366 \\
(1.0654)\end{array}$ & $\begin{array}{l}-0.9869 \\
(0.6646)\end{array}$ \\
\hline$\beta_{\mathrm{u}}$ & $\begin{array}{c}0.6477^{*} \\
(0.3388)\end{array}$ & $\begin{array}{c}0.3020 \\
(0.4346)\end{array}$ & $\begin{array}{c}0.9459^{*} \\
(0.4350)\end{array}$ & $\begin{array}{c}0.9438^{* * *} \\
(0.3643)\end{array}$ & $\begin{array}{c}0.2009 \\
(0.4534)\end{array}$ & $\begin{array}{l}-1.1723 \\
(0.5766)\end{array}$ & $\begin{array}{c}-1.1974^{* *} \\
(0.4272)\end{array}$ \\
\hline AIC & -4.9942 & -4.2591 & -6.4403 & -1.9612 & -3.6801 & -6.0746 & -2.7291 \\
\hline LL & -2.4986 & -2.1311 & -3.2217 & -0.9821 & -1.8416 & -3.0388 & -1.3661 \\
\hline \multicolumn{8}{|c|}{ 5. TVP-Rotated Gumbel } \\
\hline $\mathrm{T}_{\mathrm{L}}$ & $\begin{array}{c}0.6023^{* * *} \\
(2.5705)\end{array}$ & $\begin{array}{c}0.0933 \\
(1.2754)\end{array}$ & $\begin{array}{c}-3.1909^{\text {**** }} \\
(0.2722)\end{array}$ & $\begin{array}{c}-0.9614 \\
(0.6868)\end{array}$ & $\begin{array}{c}-2.7429^{* * *} \\
(0.0831)\end{array}$ & $\begin{array}{l}2.8801^{* * *} \\
(0.0593)\end{array}$ & $\begin{array}{c}-0.6542 \\
(1.1256)\end{array}$ \\
\hline$\alpha_{\mathrm{L}}$ & $\begin{array}{l}-0.6327 \\
(2.6545)\end{array}$ & $\begin{array}{c}0.0007 \\
(1.3383)\end{array}$ & $\begin{array}{l}3.2208^{* * * *} \\
(0.2851)\end{array}$ & $\begin{array}{c}1.3516 \\
(0.5660)\end{array}$ & $\begin{array}{l}2.5729^{* *} \\
(0.1363)\end{array}$ & $\begin{array}{c}-2.8363^{* * *} \\
(0.0008)\end{array}$ & $\begin{array}{c}0.8006^{*} \\
(1.1250)\end{array}$ \\
\hline$\beta_{\mathrm{L}}$ & $\begin{array}{l}-0.3195^{*} \\
(0.5324)\end{array}$ & $\begin{array}{c}-0.6964^{* *} \\
(0.6032)\end{array}$ & $\begin{array}{c}-0.7268^{* * *} \\
(0.0761)\end{array}$ & $\begin{array}{c}-1.1738^{* * *} \\
(0.3292)\end{array}$ & $\begin{array}{c}-0.3251^{* * *} \\
(0.1364)\end{array}$ & $\begin{array}{l}-0.2291 \\
(0.1805)\end{array}$ & $\begin{array}{c}-0.8940^{* *} \\
(0.4978)\end{array}$ \\
\hline AIC & -8.1837 & -10.3631 & -14.7231 & -3.0752 & -12.8004 & -1.8599 & -8.7060 \\
\hline LL & -4.0934 & -5.1830 & -7.3630 & -1.5391 & -6.4017 & -0.9315 & -4.3545 \\
\hline \multicolumn{8}{|c|}{ 6. TVP-Symmetrized JC } \\
\hline $\mathrm{T}_{\mathrm{U}}$ & $-24.999^{* * *}$ & $-13.946^{* * *}$ & $\begin{array}{c}-20.615^{* * *} \\
(1.0000)\end{array}$ & $\begin{array}{c}-13.169^{* * *} \\
(1.0000)\end{array}$ & $-20.785^{* * *}$ & $-13.169^{* * *}$ & $\begin{array}{l}- \\
26.612^{* * *} \\
(1.0000)\end{array}$ \\
\hline$\beta_{U}$ & $\begin{array}{c}0.0003 \\
(1.0000)\end{array}$ & $\begin{array}{l}-0.0178 \\
(1.0458)\end{array}$ & $\begin{array}{c}0.0000 \\
(1.0000)\end{array}$ & $\begin{array}{c}0.0000 \\
(1.0000)\end{array}$ & $\begin{array}{c}0.0000 \\
(1.0000)\end{array}$ & $\begin{array}{c}0.0000 \\
(1.0000)\end{array}$ & $\begin{array}{c}0.0000 \\
(1.0000)\end{array}$ \\
\hline$\alpha_{U}$ & $\begin{array}{c}0.0000 \\
(1.0000)\end{array}$ & $\begin{array}{l}-0.0001 \\
(1.0000)\end{array}$ & $\begin{array}{c}0.0000 \\
(1.0000)\end{array}$ & $\begin{array}{c}0.0000 \\
(1.0000)\end{array}$ & $\begin{array}{c}0.0000 \\
(1.0000)\end{array}$ & $\begin{array}{c}0.0000 \\
(1.0000)\end{array}$ & $\begin{array}{c}0.0000 \\
(1.0000)\end{array}$ \\
\hline $\mathrm{T}_{\mathrm{L}}$ & $\begin{array}{l}-14.063 \\
(66.079)\end{array}$ & $\begin{array}{l}-13.989 \\
(88.254)\end{array}$ & $\begin{array}{c}-7.1709 \\
(6.514)\end{array}$ & $\begin{array}{c}-13.169^{* * *} \\
(1.0000)\end{array}$ & $\begin{array}{l}-7.0216 \\
(6.2759)\end{array}$ & $\begin{array}{c}-13.169^{* * * *} \\
(1.0000)\end{array}$ & $\begin{array}{c}-14.124 \\
(68.1108)\end{array}$ \\
\hline$\beta_{\mathrm{L}}$ & $\begin{array}{l}-1.7101 \\
(14.545)\end{array}$ & $\begin{array}{l}-0.5917 \\
(7.1618)\end{array}$ & $\begin{array}{l}-0.7553 \\
(2.8388)\end{array}$ & $\begin{array}{c}0.0000 \\
(1.0000)\end{array}$ & $\begin{array}{l}-0.5784 \\
(1.6843)\end{array}$ & $\begin{array}{c}0.0000 \\
(1.0000)\end{array}$ & $\begin{array}{c}-0.8976 \\
(7.5618)\end{array}$ \\
\hline$\alpha_{\mathrm{L}}$ & $\begin{array}{l}-0.0173 \\
(1.0106)\end{array}$ & $\begin{array}{l}-0.0139 \\
(1.0140)\end{array}$ & $\begin{array}{l}-0.0087 \\
(1.0003)\end{array}$ & $\begin{array}{c}0.0000 \\
(1.0000)\end{array}$ & $\begin{array}{l}-0.0090 \\
(1.0003)\end{array}$ & $\begin{array}{c}0.0000 \\
(1.0000)\end{array}$ & $\begin{array}{l}-0.0184 \\
(1.0121)\end{array}$ \\
\hline AIC & -3.5336 & -4.3452 & -8.6467 & 15.9571 & -6.8685 & 14.7628 & 1.9894 \\
\hline \multirow{2}{*}{\multicolumn{8}{|c|}{$\begin{array}{l}\text { LL } \\
\text { 7. TVP-Student's } \boldsymbol{t}\end{array}$}} \\
\hline & & & & & & & \\
\hline$\Psi_{0}$ & $\begin{array}{c}0.0341 \\
(0.0709)\end{array}$ & $\begin{array}{c}0.0519 \\
(0.0641)\end{array}$ & $\begin{array}{c}0.0955 \\
(0.0997)\end{array}$ & $\begin{array}{l}-0.0924 \\
(0.0838)\end{array}$ & $\begin{array}{c}0.0589 \\
(0.0624)\end{array}$ & $\begin{array}{l}-0.0342 \\
(0.0495)\end{array}$ & $\begin{array}{l}0.0251^{* *} \\
(0.0632)\end{array}$ \\
\hline
\end{tabular}




\begin{tabular}{lccccccc}
\hline \hline $\mathrm{E}$ & 0.0000 & 0.0000 & 0.0000 & 0.0000 & 0.0000 & 0.0000 & 0.0000 \\
$\Psi_{1}$ & -0.0235 & -0.0316 & 0.0824 & -0.0617 & -0.0056 & -0.0666 & -0.1031 \\
& $(0.0563)$ & $(0.0506)$ & $(0.0552)$ & $(0.0878)$ & $(0.0506)$ & $(0.0604)$ & $(0.0748)$ \\
$\Psi_{2}$ & -0.0783 & 0.0546 & $-1.9593^{* * *}$ & -1.3146 & -0.0128 & -0.0524 & -0.9083 \\
& $(2.6645)$ & $(1.4573)$ & $(0.0498)$ & $(0.8790)$ & $(0.9995)$ & $(1.1366)$ & $(1.0073)$ \\
$\mathrm{Y}$ & $5.0000^{* * *}$ & $5.0000^{* * *}$ & $5.0000^{* * *}$ & $5.0000^{* * *}$ & $5.0000^{* * *}$ & $5.0000^{* * *}$ & $5.0000^{* * *}$ \\
& $(1.0000)$ & $(1.0000)$ & $(1.0000)$ & $(1.0000)$ & $(1.0000)$ & $(1.0000)$ & $(1.0000)$ \\
$\mathrm{AIC}$ & 4.7894 & 14.1761 & -13.5637 & 12.0865 & -5.2582 & 40.7376 & 30.3028 \\
$\mathrm{LL}$ & 2.3927 & 7.0861 & -6.7839 & 6.0413 & -2.6311 & 20.3668 & 15.1494 \\
& & & & & & & \\
\hline
\end{tabular}

Note: In the above table, we present ML estimates for time varying and time invariant bivariate copulas. Values in parenthesis highlight standard errors. AIC values are adjusted for small sample bias for the family of bivariate copulas. We highlight the best fitted copulas for each Bitcoin- precious metal pair through minimum AIC value as bold text. *,** and $^{* * *}$ indicate significance at the $10 \%, 5 \%, 1 \%$ levels, respectively.

Figure 3 presents dynamic dependence over time for the best fitted time varying copulas. Over the period, we see varying dependence between Bitcoin and Islamic indices however magnitude of dependence varies for each Bitcoin-Islamic index pair. DJIUK exhibits high magnitude of dependence with Bitcoin which remains consistent till the end of 2018. We witness volatile dependence structure between Bitcoin and DJIJP across the sample period however minimal dependence of Bitcoin is observed with DJICA. The presence of time varying dependence structure between Bitcoin and Islamic equity markets highlight that despite of low unconditional correlation and difference in return pattern, Bitcoin and Islamic indices exhibit differing underlying dependence implying dynamic relationship. The presence of dynamic dependence calls for further investigation of spillover effect between Bitcoin and Islamic indices to infer implications for portfolio diversification. 


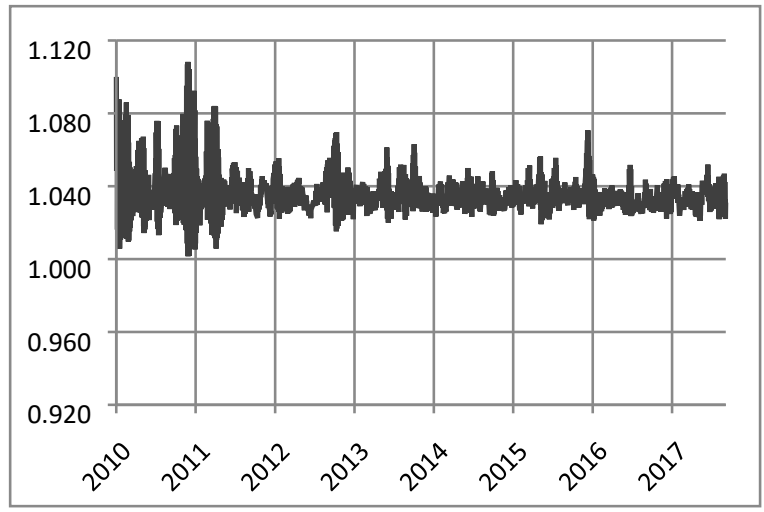

a) TVP Rotated Gumbel - DJIUK

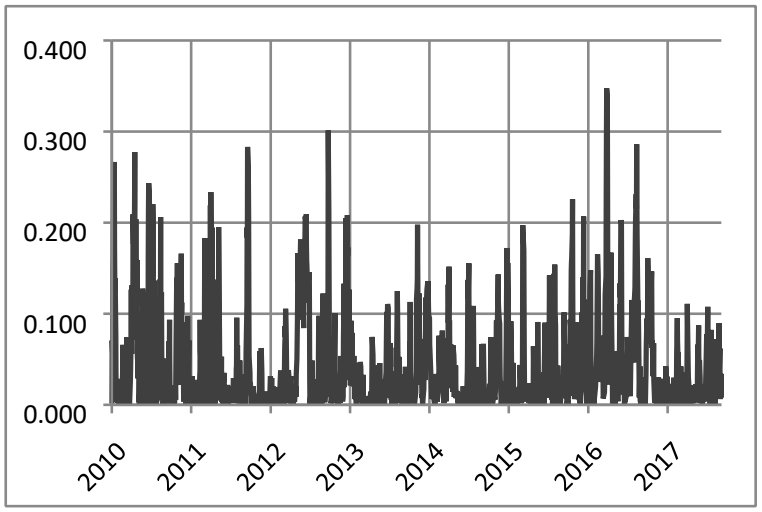

b) TVP Rotated Clayton - DJIIJP

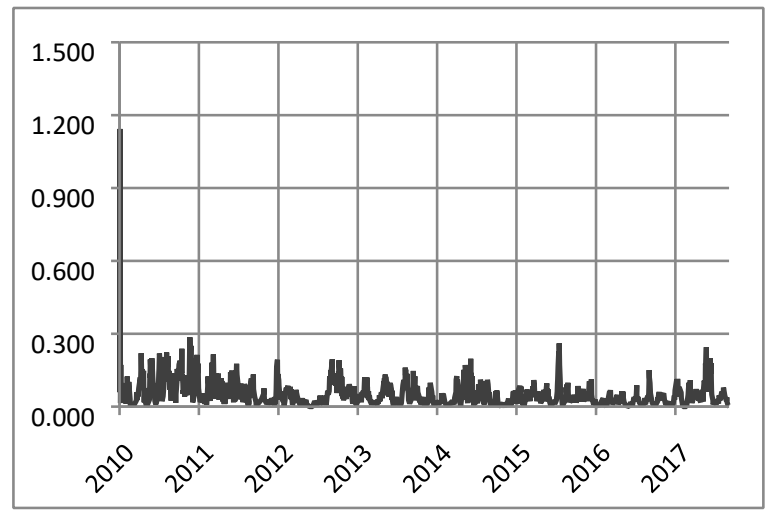

c) TVP Clayton - DJICA

Figure 3. Dependence structure on the best fitted time-varying copulas

\subsection{Risk dependence and CoVaR}

Above mentioned copula results suggest the presence of dependence structure between Bitcoin and Islamic indices pair and therefore we make further analysis to quantify risk spillover between these two asset classes. Table 4 reports $\mathrm{VaR}, \mathrm{CoVaR}$ and $\Delta \mathrm{CoVaR}$ results for spillover from Bitcoin to Islamic equity markets and vice versa. In Table 4, we clearly see that the both upside and downside VaR for Bitcoin is higher than the VaR of all sampled Islamic markets. These results confirm the speculative nature of Bitcoin and the associated risks. The riskier nature of Bitcoin market compared to Islamic equity market is reflected not only by the average upside and downside VaR statistics but also by the standard deviation values in parenthesis. Among all Islamic 
indices, almost all Islamic indices exhibit low variation in returns as depicted by their standard deviation values. These results suggest that safe investment nature of Islamic indices which prohibit speculation and returns based real assets. This is quite contrary to the speculative nature of Bitcoin which is based on speculation and is supported by its exuberated growth since 2017.

In terms of comparison between $\mathrm{VaR}$ and $\mathrm{CoVaR}$ measures, we present our results for spillover from Bitcoin to Islamic and Islamic indices to Bitcoin market, respectively. We can see that in Table 4 (Panel a) for spillover from Bitcoin to Islamic market, the CoVaR measure of Islamic equity markets exceeds their respective VaR estimates. This result is quite logical since the speculative nature of Bitcoin does have a spillover effect towards other asset classes. These result might be of great significance since Islamic equities are considered to have hedging abilities however in our analysis, they also appear as a recipient of spillover from Bitcoin. We also witness consistency in our results for all Islamic indices and for both upside and downside risk spillover. However, empirical results of Table 4 (Panel b) appear quite interesting since we witness spillover from Islamic indices towards the Bitcoin market as well. Bitcoin that is already considered to have speculative nature also acts recipient of systemic risk due to the turbulence in returns of Islamic markets. These results also suggest that the equity markets, no matter how different they become in terms of their characteristics, composition, nature and returns, are somehow integrated through an underlying relationship. However, in which case, the magnitude of such spillover from one market to another becomes important. Our results in Table 4 are also tested for the null hypothesis of significant different results between $\mathrm{VaR}$ and $\mathrm{CoVaR}$ measure for both upside and downside risk measures and from returns spillover from Bitcoin to Islamic markets and vice versa, which is rejected in all cases and for all Islamic equity markets. 
Table 4. Descriptive Statistics and KS Bootstrapping Test for VaR and CoVaR (From Bitcoin to Islamic Indices)

\begin{tabular}{|c|c|c|c|c|c|c|}
\hline & \multicolumn{3}{|c|}{ Downside } & \multicolumn{3}{|c|}{ Upside } \\
\hline & $\mathrm{VaR}$ & $\mathrm{CoVaR}$ & $\begin{array}{l}\mathrm{H}_{0}: \operatorname{CoVaR}=\mathrm{VaR} \\
\mathrm{H}_{1}: \operatorname{CoVaR}<\mathrm{VaR}\end{array}$ & VaR & $\mathrm{CoVaR}$ & $\begin{array}{l}\mathrm{H}_{0}: \mathrm{CoVaR}=\mathrm{VaR} \\
\mathrm{H}_{1}: \mathrm{CoVaR}>\mathrm{VaR}\end{array}$ \\
\hline DJIM & $\begin{array}{l}-0.0138 \\
(0.0001)\end{array}$ & $\begin{array}{l}-0.0177 \\
(0.0002)\end{array}$ & $\begin{array}{c}0.2725 \\
{[0.0000]}\end{array}$ & $\begin{array}{c}0.0151 \\
(0.0001)\end{array}$ & $\begin{array}{c}0.0190 \\
(0.0002)\end{array}$ & $\begin{array}{c}0.2650 \\
{[0.0000]}\end{array}$ \\
\hline IMUS & $\begin{array}{l}-0.0157 \\
(0.0001)\end{array}$ & $\begin{array}{l}-0.0391 \\
(0.0004)\end{array}$ & $\begin{array}{c}0.7839 \\
{[0.0000]}\end{array}$ & $\begin{array}{c}0.0173 \\
(0.0002)\end{array}$ & $\begin{array}{c}0.0408 \\
(0.0004)\end{array}$ & $\begin{array}{c}0.8224 \\
{[0.0000]}\end{array}$ \\
\hline DJIEU & $\begin{array}{l}-0.0201 \\
(0.0002)\end{array}$ & $\begin{array}{l}-0.0567 \\
(0.0005)\end{array}$ & $\begin{array}{c}0.8433 \\
{[0.0000]}\end{array}$ & $\begin{array}{c}0.0209 \\
(0.0002)\end{array}$ & $\begin{array}{c}0.0575 \\
(0.0005)\end{array}$ & $\begin{array}{c}0.8333 \\
{[0.0000]}\end{array}$ \\
\hline DJIAP & $\begin{array}{l}-0.0157 \\
(0.0001)\end{array}$ & $\begin{array}{l}-0.0384 \\
(0.0003)\end{array}$ & $\begin{array}{c}0.8348 \\
{[0.0000]}\end{array}$ & $\begin{array}{c}0.0167 \\
(0.0001)\end{array}$ & $\begin{array}{c}0.0394 \\
(0.0003)\end{array}$ & $\begin{array}{c}0.8283 \\
{[0.0000]}\end{array}$ \\
\hline DJIUK & $\begin{array}{l}-0.0210 \\
(0.0002)\end{array}$ & $\begin{array}{l}-0.0564 \\
(0.0005)\end{array}$ & $\begin{array}{c}0.8957 \\
{[0.0000]}\end{array}$ & $\begin{array}{c}0.0223 \\
(0.0002)\end{array}$ & $\begin{array}{c}0.2286 \\
(0.0020)\end{array}$ & $\begin{array}{c}1.0000 \\
{[0.0000]}\end{array}$ \\
\hline DJIJP & $\begin{array}{l}-0.0202 \\
(0.0001)\end{array}$ & $\begin{array}{l}-0.0414 \\
(0.0004)\end{array}$ & $\begin{array}{c}0.7769 \\
{[0.0000]}\end{array}$ & $\begin{array}{c}0.0217 \\
(0.0001)\end{array}$ & $\begin{array}{c}0.0350 \\
(0.0002)\end{array}$ & $\begin{array}{c}0.6946 \\
{[0.0000]}\end{array}$ \\
\hline DJICA & $\begin{array}{l}-0.0232 \\
(0.0002)\end{array}$ & $\begin{array}{l}-0.1060 \\
(0.0016)\end{array}$ & $\begin{array}{c}0.9386 \\
{[0.0000]}\end{array}$ & $\begin{array}{c}0.0234 \\
(0.0002)\end{array}$ & $\begin{array}{c}0.0686 \\
(0.0005)\end{array}$ & $\begin{array}{c}0.9172 \\
{[0.0000]}\end{array}$ \\
\hline
\end{tabular}

\section{Panel b: From Islamic to Bitcoin Market}

\begin{tabular}{|c|c|c|c|c|c|c|}
\hline & \multicolumn{3}{|c|}{ Downside } & \multicolumn{3}{|c|}{ Upside } \\
\hline & VaR & CoVaR & $\begin{array}{c}\mathrm{H}_{0}: \mathrm{CoVaR}=\mathrm{VaR} \\
\mathrm{H} 1: \mathrm{CoVaR}<\mathrm{VaR}\end{array}$ & VaR & $\mathrm{CoVaR}$ & $\begin{array}{l}\mathrm{H}_{0}: \mathrm{CoVaR}=\mathrm{VaR} \\
\mathrm{H}_{1}: \mathrm{CoVaR}>\mathrm{VaR}\end{array}$ \\
\hline DJIM & $\begin{array}{l}-0.1100 \\
(0.0016)\end{array}$ & $\begin{array}{l}-0.1403 \\
(0.0021)\end{array}$ & $\begin{array}{c}0.1652 \\
{[0.0000]}\end{array}$ & $\begin{array}{c}0.1160 \\
(0.0017)\end{array}$ & $\begin{array}{c}0.1460 \\
(0.0021)\end{array}$ & $\begin{array}{c}0.1637 \\
{[0.0000]}\end{array}$ \\
\hline IMUS & $\begin{array}{l}-0.1100 \\
(0.0016)\end{array}$ & $\begin{array}{l}-0.2706 \\
(0.0039)\end{array}$ & $\begin{array}{c}0.5654 \\
{[0.0000]}\end{array}$ & $\begin{array}{c}0.1160 \\
(0.0017)\end{array}$ & $\begin{array}{c}0.2765 \\
(0.0040)\end{array}$ & $\begin{array}{c}0.5604 \\
{[0.0000]}\end{array}$ \\
\hline & -0.1100 & -0.3116 & 0.6292 & 0.1160 & 0.3175 & 0.6297 \\
\hline DJIEU & $(0.0016)$ & $(0.0045)$ & [0.0000] & $(0.0017)$ & $(0.0045)$ & {$[0.0000]$} \\
\hline DJIAP & $\begin{array}{l}-0.1100 \\
(0.0016)\end{array}$ & $\begin{array}{l}-0.2689 \\
(0.0039)\end{array}$ & $\begin{array}{c}0.5629 \\
{[0.0000]}\end{array}$ & $\begin{array}{c}0.1160 \\
(0.0017)\end{array}$ & $\begin{array}{c}0.2749 \\
(0.0039)\end{array}$ & $\begin{array}{c}0.5569 \\
{[0.0000]}\end{array}$ \\
\hline DJIUK & $\begin{array}{l}-0.1100 \\
(0.0016)\end{array}$ & $\begin{array}{l}-0.1759 \\
(0.0026)\end{array}$ & $\begin{array}{c}0.3114 \\
{[0.0000]}\end{array}$ & $\begin{array}{c}0.1160 \\
(0.0017)\end{array}$ & $\begin{array}{c}0.1818 \\
(0.0026)\end{array}$ & $\begin{array}{c}0.3064 \\
{[0.0000]}\end{array}$ \\
\hline DJIJP & $\begin{array}{l}-0.1100 \\
(0.0016)\end{array}$ & $\begin{array}{c}0.1814 \\
(0.0027)\end{array}$ & $\begin{array}{c}0.3288 \\
{[0.0000]}\end{array}$ & $\begin{array}{c}0.1160 \\
(0.0017)\end{array}$ & $\begin{array}{c}0.2315 \\
(0.0040)\end{array}$ & $\begin{array}{c}0.4351 \\
{[0.0000]}\end{array}$ \\
\hline DJICA & $\begin{array}{l}-0.1100 \\
(0.0016)\end{array}$ & $\begin{array}{l}-0.5558 \\
(0.0132)\end{array}$ & $\begin{array}{c}0.7081 \\
{[0.0000]}\end{array}$ & $\begin{array}{c}0.1160 \\
(0.0017)\end{array}$ & $\begin{array}{c}0.3378 \\
(0.0050)\end{array}$ & $\begin{array}{c}0.6442 \\
{[0.0000]}\end{array}$ \\
\hline
\end{tabular}

Note: Values in parenthesis represents standard errors and p-values are in brackets.

Figures 4 and 5 show graphical representation of our results for $\mathrm{VaR}$ and $\mathrm{CoVaR}$ which support statistics of Table 4. On making comparison between the VaR of Islamic indices with 
Bitcoin in Figures 4 and 5, respectively, we witness that $\mathrm{VaR}$ of later is far higher than that of Islamic equity markets. These results suggest the speculative nature of Bitcoin compared with other equity markets. In Figure 4, we can also see that the conditional VaR of Islamic indices is greater than its VaR, suggesting considerable spillover from Bitcoin to Islamic indices. We also report interesting results in Figure 5 as $\mathrm{CoVaR}$ of Bitcoin also exceeds its VaR suggesting the spillover of risk from Islamic to Bitcoin market. However, the difference between CoVaR and VaR of Islamic indices is much greater than their difference in Bitcoin market, suggesting higher sensitivity of Islamic indices to Bitcoin market.

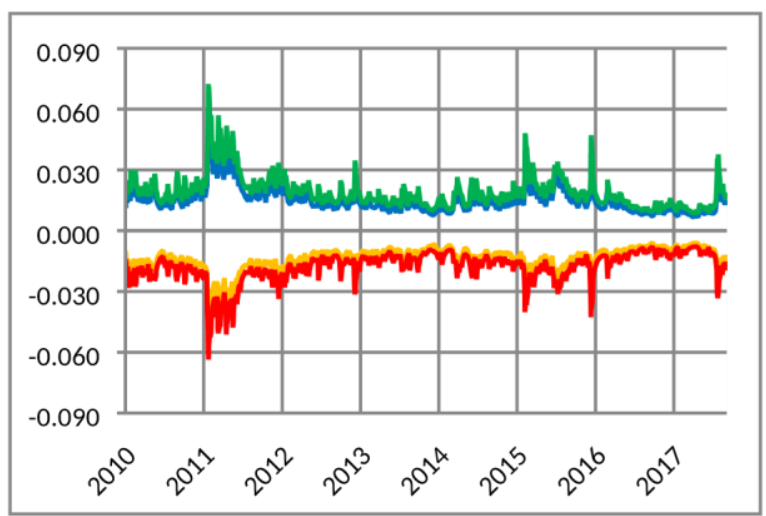

a) DJIM

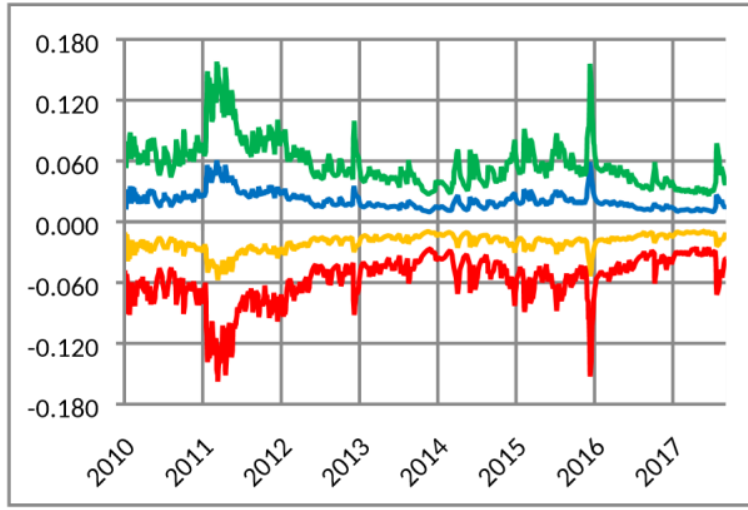

c) DJIEU

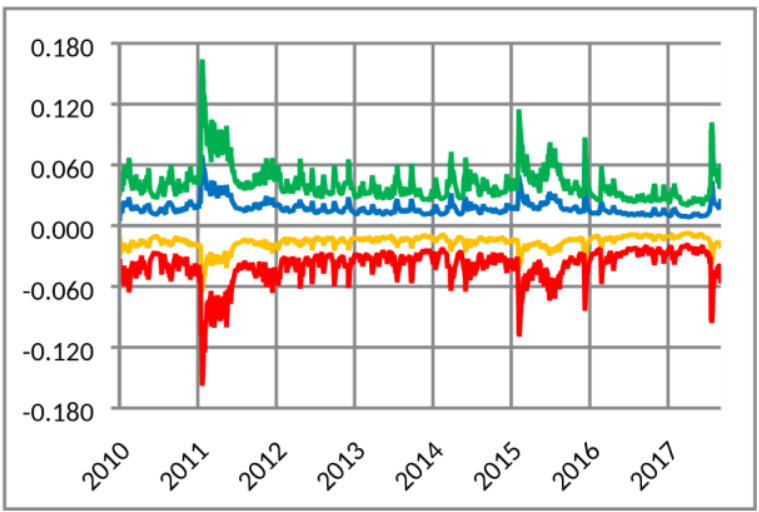

b) IMUS

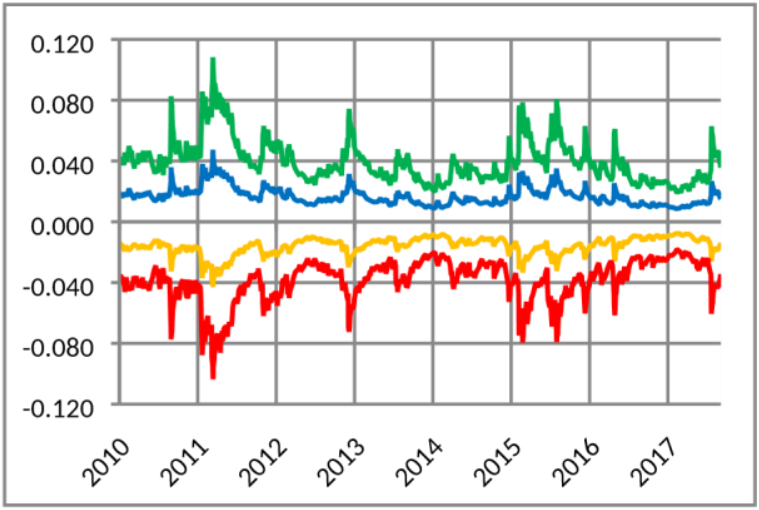

d) DJIAP 


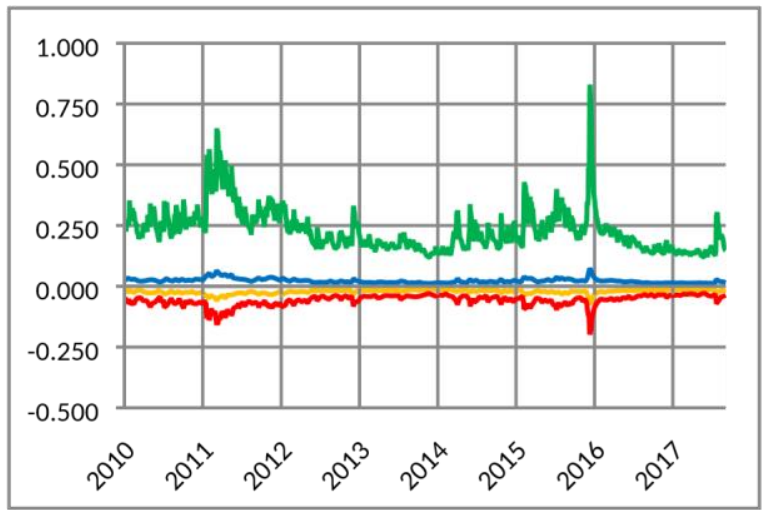

e) DJIUK

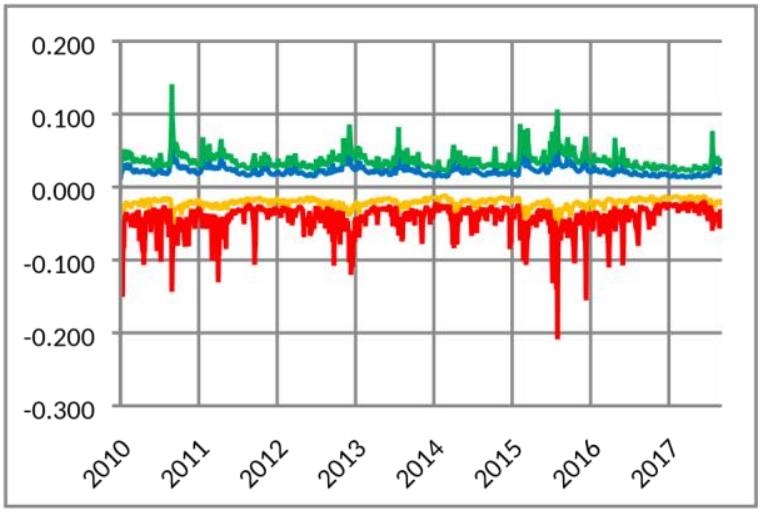

f) DJJP

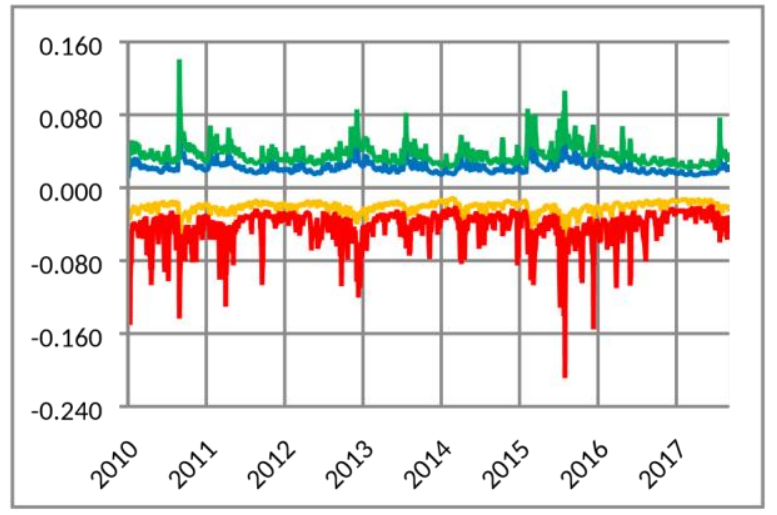

g) DJICA

Figure 4. Upside and downside VaR-CoVaR from Bitcoin to Islamic market

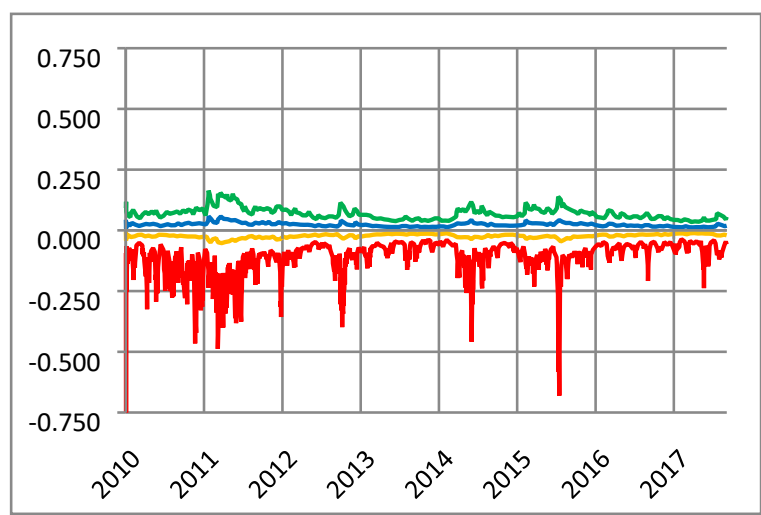

a) DJIM

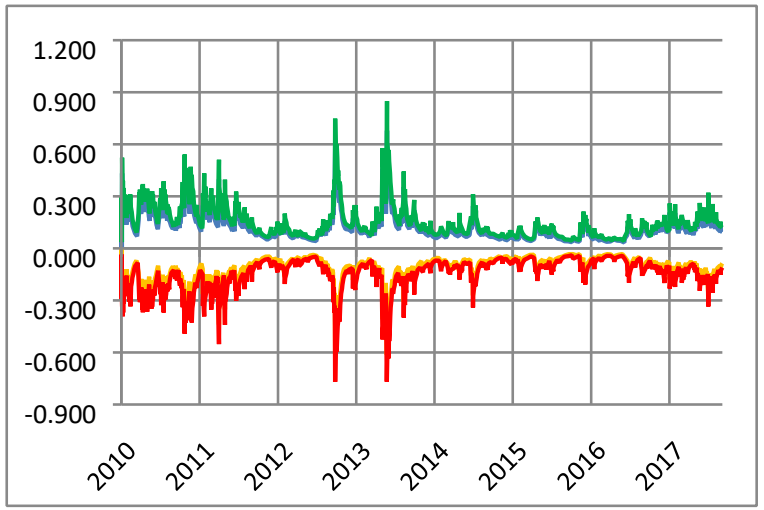

b) IMUS 


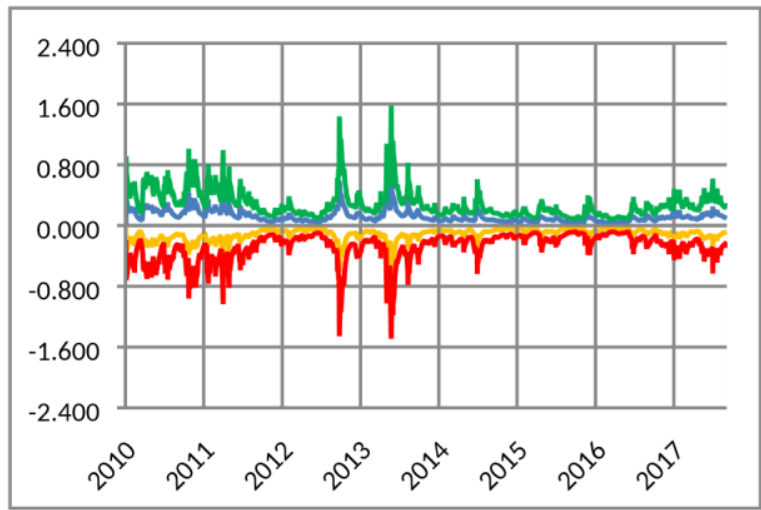

c) DJIEU

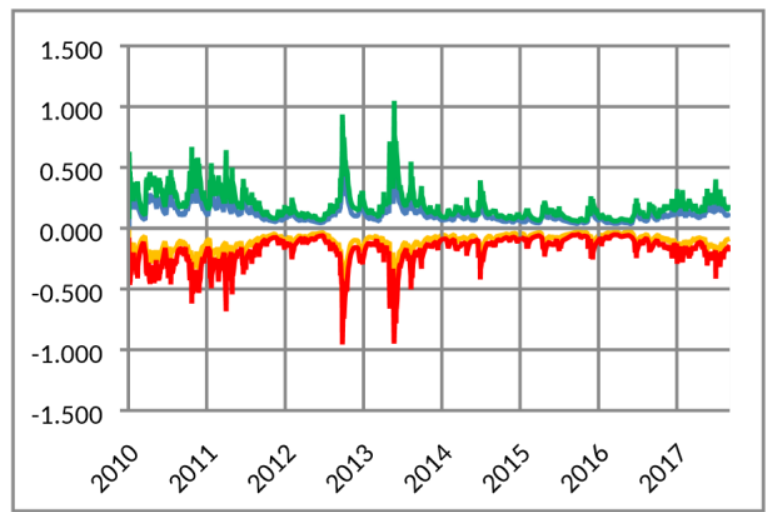

e) DJIUK

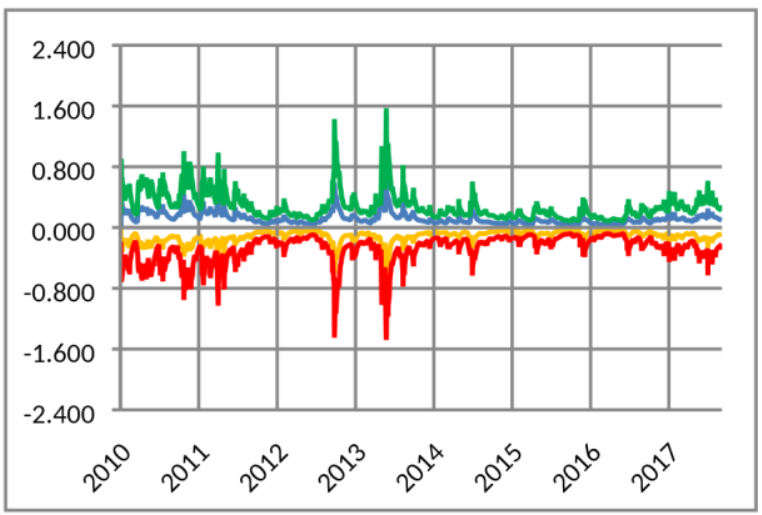

d) DJIAP

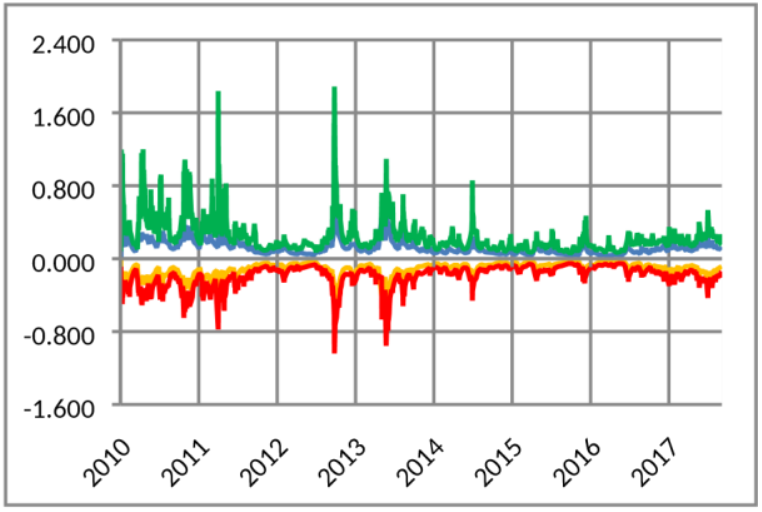

f) DJIJP

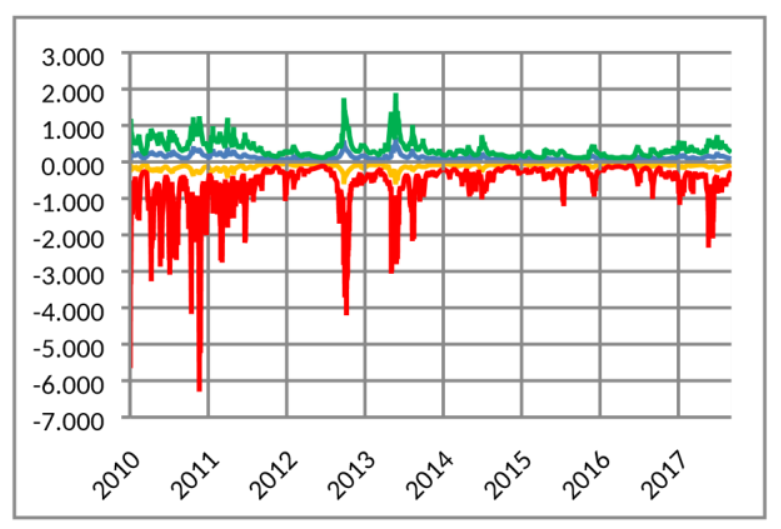

g) DJICA

Figure 5. Upside and downside VaR-CoVaR from Islamic to Bitcoin market

Table 5 reports results for $\Delta \mathrm{CoVaR}$ for analyzing the spillover between Bitcoin and Islamic indices. We follow the work of Adrian and Brunnermeier (2011) in estimating $\Delta \mathrm{CoVaR}$ results. We report results for bidirectional spillover i.e. from Bitcoin to Islamic equity market and from 
Islamic indices to Bitcoin market. For spillover from Bitcoin to Islamic indices, we report significant difference between upside and downside $\Delta \mathrm{CoVaR}$ statistics, suggesting the nature of spillover between these two asset classes as asymmetric. Furthermore, we can also see that the downside $\Delta \mathrm{CoVaR}$ measure is greater than the upside $\Delta \mathrm{CoVaR}$ measure, with only DJIUK as an exception. These findings are important for investors in having short and long positions in their investments while making portfolio between Islamic indices and Bitcoin. Similarly, for spillover from Islamic indices to Bitcoin market, we also report significant differences between upside and downside $\Delta \mathrm{CoVaR}$ measure. Again for spillover from Islamic to Bitcoin market, we see values of downside $\Delta \mathrm{CoVaR}$ greater than the upside $\Delta \mathrm{CoVaR}$. These results suggest more risks for investors in case the market faces bearish market conditions.

Table 5. Descriptive Statistics and KS Bootstrapping Test for $\Delta \mathrm{CoVaR}$

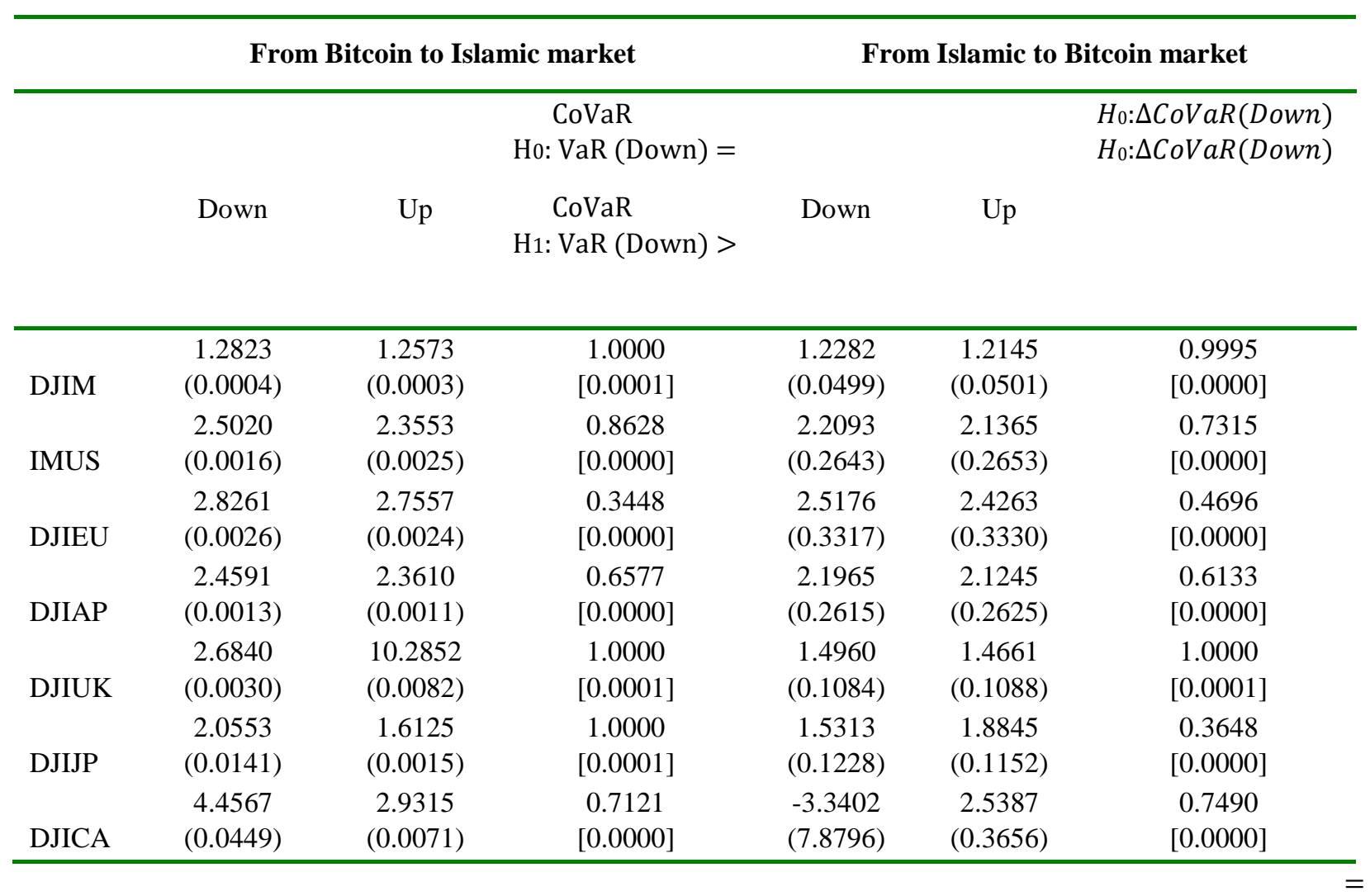


Note: Values in parenthesis represents standard errors and p-values are in brackets.

Figures 6 and 7 plot the dynamics of $\Delta \mathrm{CoVaR}$ measures for spillover from i) Bitcoin to Islamic market (Figure 6), and ii) Islamic to Bitcoin market (Figure 7). These graphical depictions confirm our findings in Table 5 as we report evidence of asymmetric behavior of risk spillover between upside and downside $\triangle \mathrm{CoVaR}$. In all cases except DJIUK for spillover from Bitcoin towards Islamic markets, we witness higher values of downside $\Delta \mathrm{CoVaR}$ compared with upside $\Delta \mathrm{CoVaR}$. These differing statistics for risk measures may have important as well as different implications for investors based on their risk preferences. 


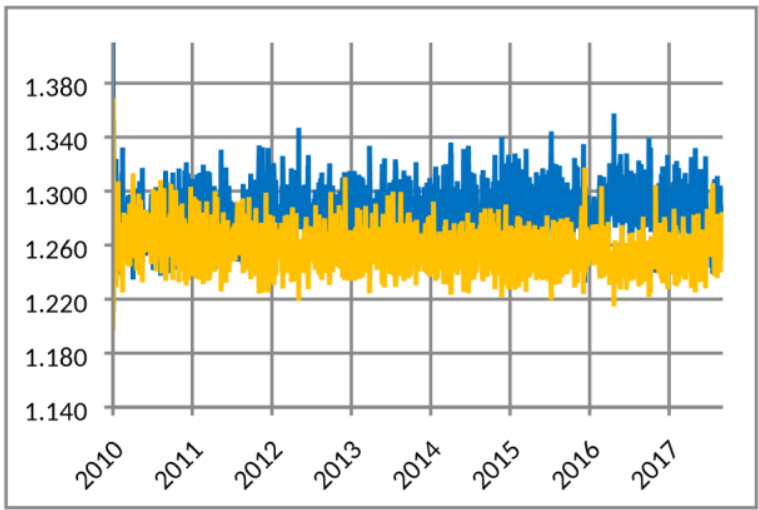

a) DJIM

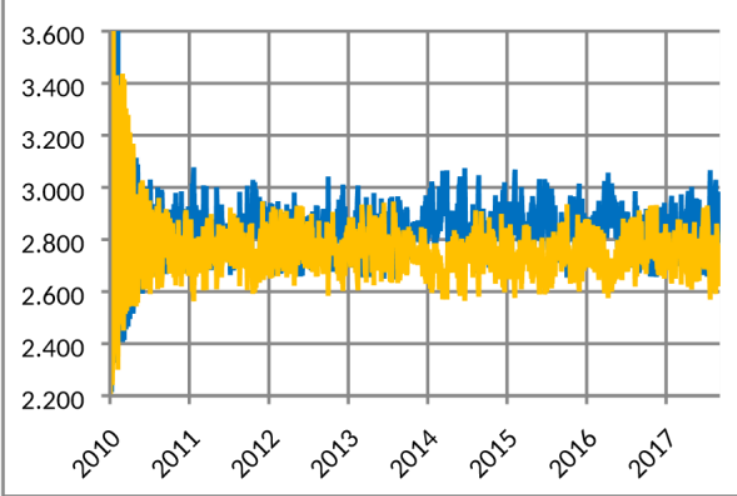

c) DJIEU

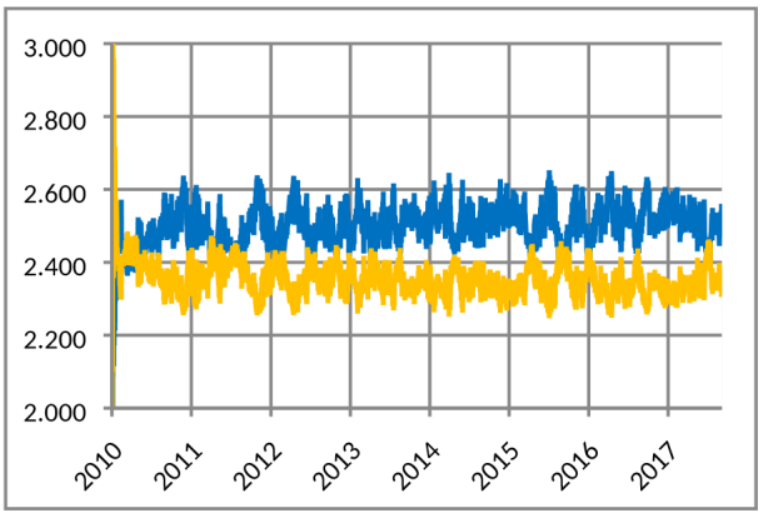

b) IMUS

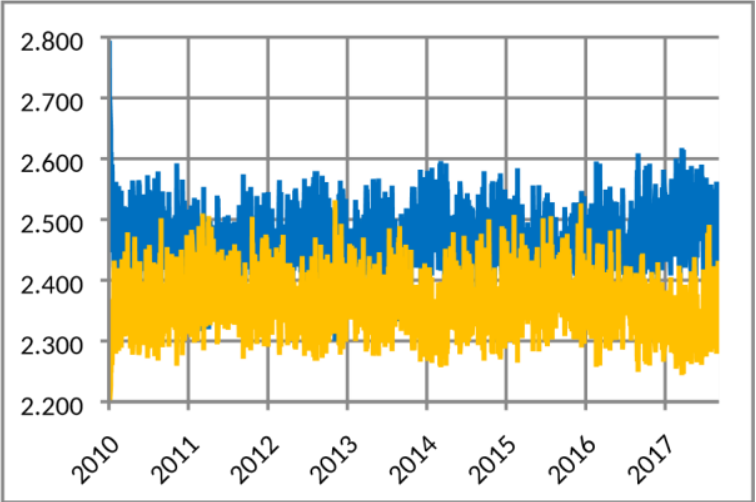

d) DJIAP 


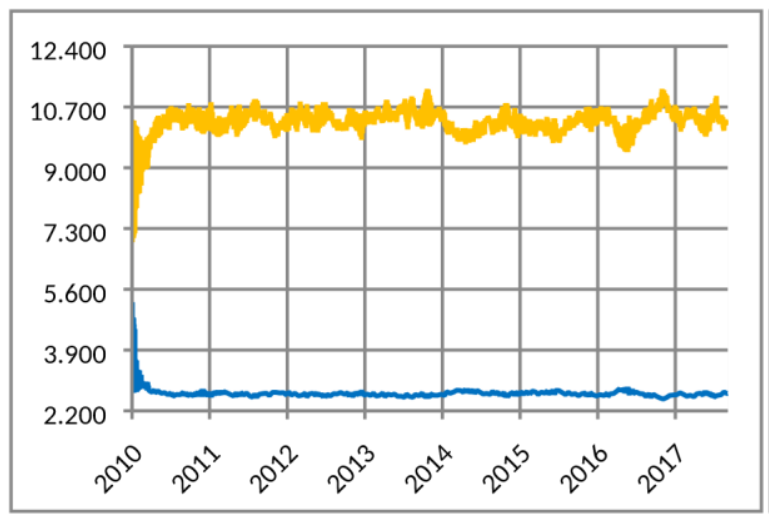

e) DJIUK

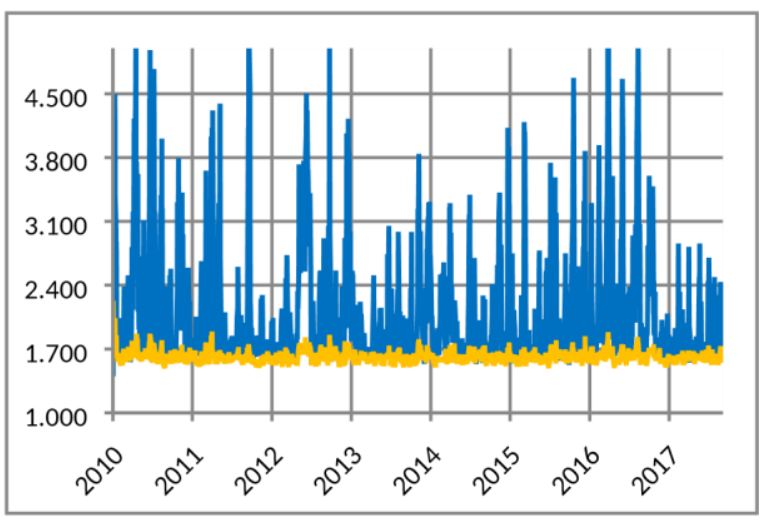

f) DJIJP

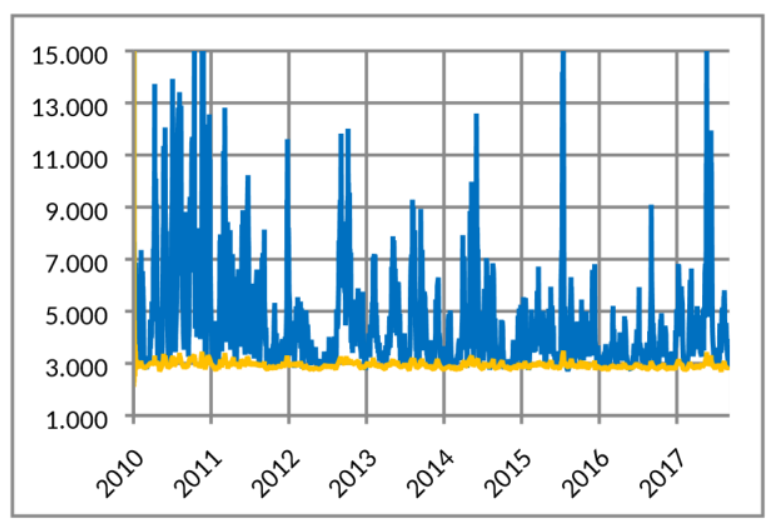

g) DJICA

Figure 6. Upside and downside $\Delta \mathrm{CoVaR}$ from Bitcoin to Islamic market

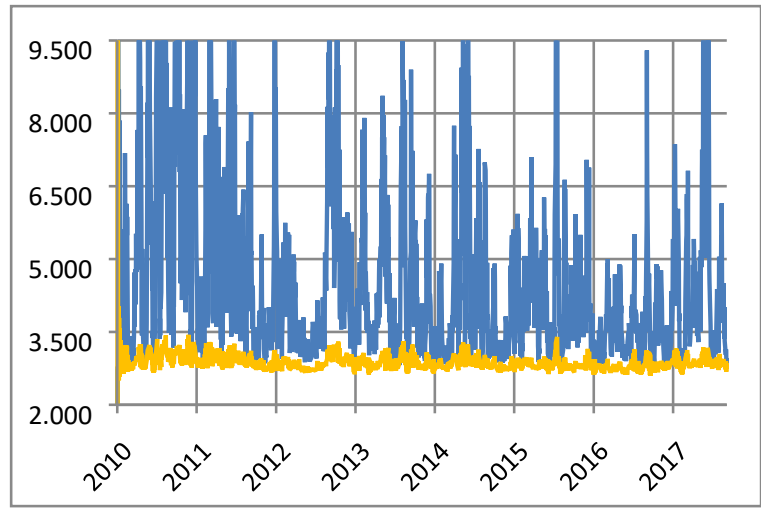

a) DJIM

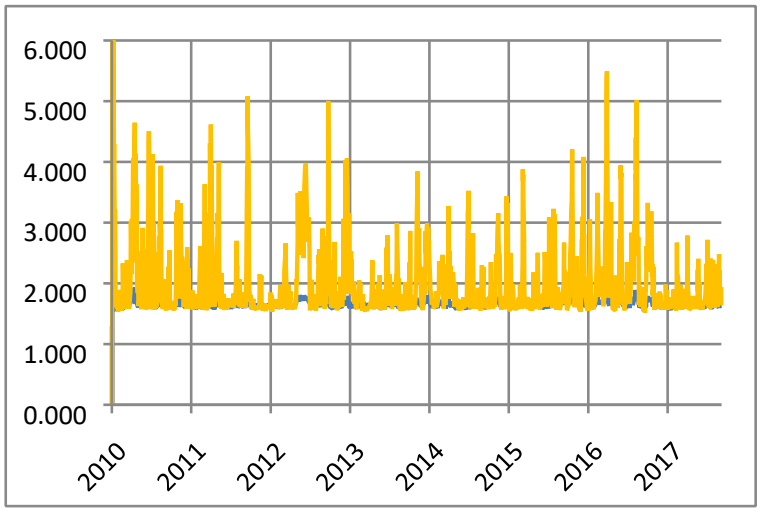

b) IMUS 


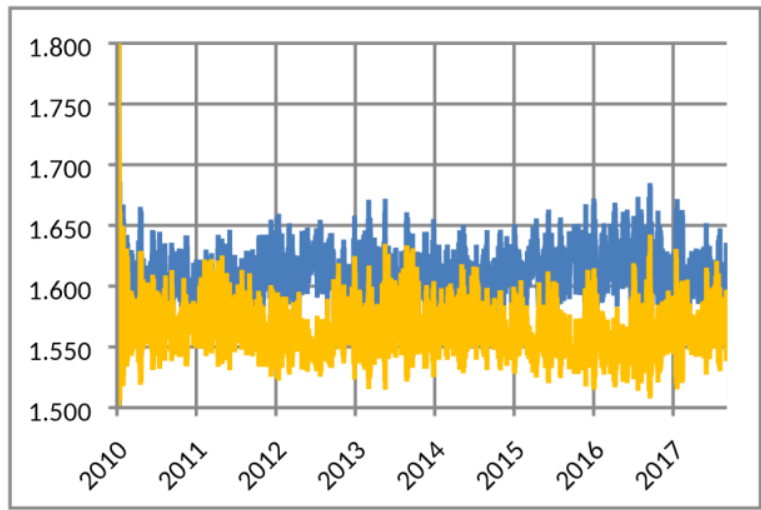

c) DJIEU

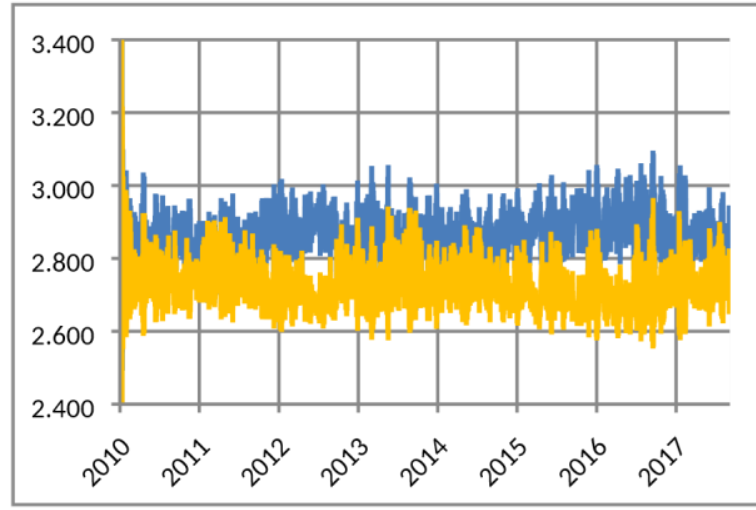

e) DJIUK

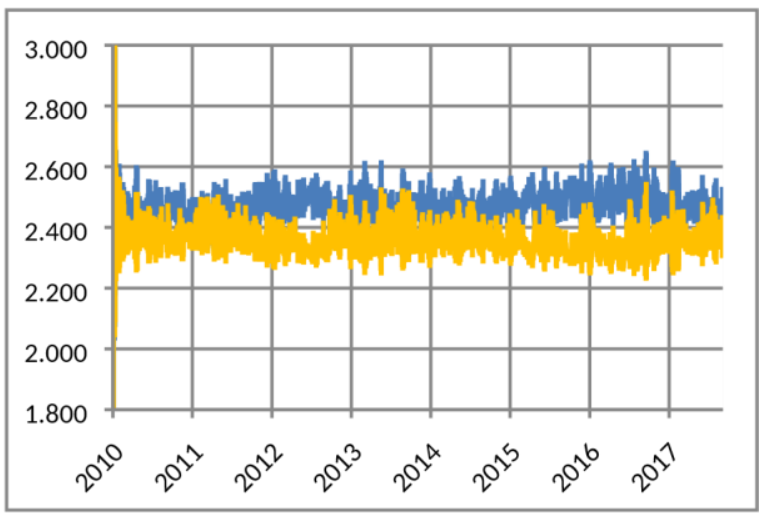

d) DJIAP

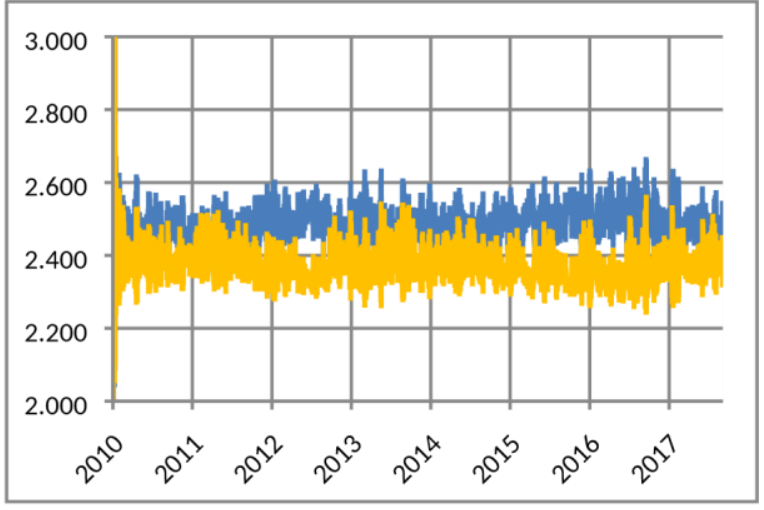

f) DJIJP

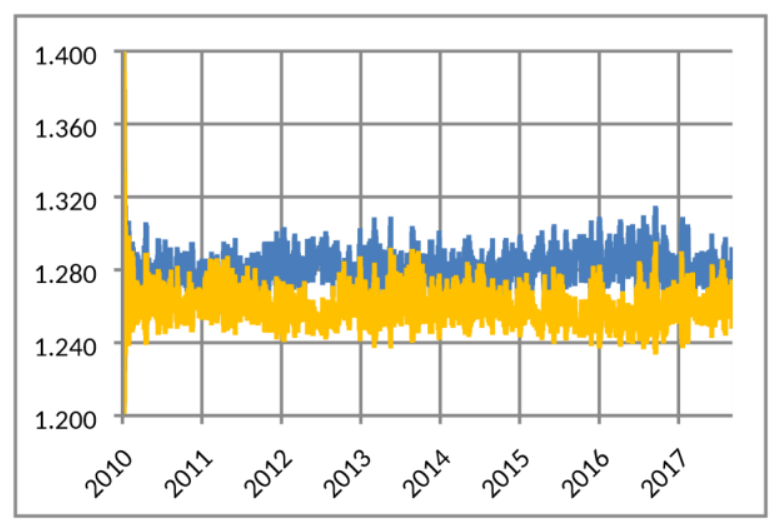

g) DJICA

Figure 7. Upside and Downside $\triangle \mathrm{CoVaR}$ from Islamic to Bitcoin Market

Table 5 also reports asymmetric results with substantial implications for financial decision making. For this purpose, we compare asymmetric upside and downside risk spillover between Bitcoin and Islamic indices. To make such comparison, we equate upside CoVaR normalized by upside VaR with downside CoVaR normalized by downside VaR by using K-S statistic for 
measuring significant differences between upside and downside spillover. Furthermore, we also consider downside $\triangle \mathrm{CoVaR}$ against upside $\triangle \mathrm{CoVaR}$. Using results in Table 5, we report asymmetric behavior between upside and downside risk spillover between Bitcoin and Islamic equity markets. Moreover, we also investigate the presence of any substantial asymmetries between $\Delta \mathrm{CoVaR}$ measure. Such results are important for investors considering Islamic indices and Bitcoin in a portfolio especially when market experiences extreme return movements. A decline in Bitcoin prices may lead towards low average Islamic equity market returns, which may result in overall portfolio deteriorating returns despite of seemingly low correlation between both asset classes.

\section{Conclusions}

Increasing integration of financial and equity markets at one end provides stability and efficient functioning, yet at the other end becomes challenging for investors in achieving high diversification benefits. Though increasing investment opportunities i.e. alternative investments, energy commodities and Islamic asset classes, etc. can facilitate international investors in diversifying their portfolio, understanding their underlying relationship is of utmost importance. Among many contemporary assets since last decade, Bitcoin among other crypto currencies has gained much importance among investment as well as international research community.

In this study, we investigate the relationship between Bitcoin and Islamic equity indices under extreme market conditions. Selection of Bitcoin is based on its capability to earn abnormal returns over the last couple of decades whereas Islamic equity market present itself as an effective hedging investment opportunity together in a portfolio. However, understanding dynamics of 
relationship between Bitcoin and Islamic equity market is important. For this purpose, we investigate the long memory properties with significant results and use the extracted residuals to model time invariant and time varying copula framework. Results of copula framework highlight that except DJIUK, DJIJP and DJICA (paired with Bitcoin), all Islamic indices are exhibit time invariant behavior with symmetrical tail dependence. This suggests that when paired with Bitcoin, these assets do not show variation across different time periods, thereby providing optimal returns during unstable and turbulent market conditions. However, DJIUK and DJICA exhibit extreme lower tail dependence and DJIJP demonstrate upper tail dependence, when paired with Bitcoin. Therefore, among other indices, DJIUK and DJICA requires a careful look at the return patterns of Bitcoin being a speculative asset.

We further investigate spillover phenomena between these two asset classes and report significant bidirectional spillover between Bitcoin and Islamic equity market. The Value at risk for Bitcoin appears higher than the $\mathrm{VaR}$ of Islamic indices confirming its speculative nature. Regarding the upside and downside risk measures, downside VaR dominates in value than the upside VaR highlighting more risk for investors under extreme market conditions. We also report presence of asymmetry between downside $\Delta \mathrm{CoVaR}$ and upside $\Delta \mathrm{CoVaR}$ with downside $\mathrm{CoVaR}$ more prominent than upside $\Delta \mathrm{CoVaR}$ thereby having implication for investors under bearish market conditions. These results suggest investors to keep an eye on the downside price movements of Bitcoin due to the presence of an asymmetric behavior of conditional VaR for both Islamic equity market and Bitcoin.

\section{Acknowledgment:}


This work was supported by the Ministry of Education of the Republic of Korea and the National Research Foundation of Korea (NRF-2017S1A5B8057488).

\section{References}

Abadie, A., 2002. Bootstrap tests for distributional treatment effects in instrumental variable models. Journal of the American Statistical Association, 97(457), pp. 284-292.

Abbes, M.B., Trichilli, Y., 2015. Islamic stock markets and potential diversification benefits. Borsa Istanbul Review, 15(2), pp. 93-105.

Abdullah, F., Hassan, T., Mohamad, S., 2007. Investigation of performance of Malaysian Islamic unit trust funds: Comparison with conventional unit trust funds. Managerial Finance, 33(2), pp. 142-153.

Adrian, T., Brunnermeier, M.K., 2011. CoVaR. FRB of New York Staff Report No. 348. Available at SSRN: https://ssrn.com/abstract=1269446 or http://dx.doi.org/10.2139/ssrn.1269446.

Ahmad, W., Rais, S., Shaik, A.R., 2018. Modelling the directional spillovers from DJIM Index to conventional benchmarks: Different this time? The Quarterly Review of Economics and Finance, 67, pp. 14-27.

Ahmed, H., Elsayed, A.H., 2018. Are Islamic and conventional capital markets decoupled? Evidence from stock and bonds/sukuk markets in Malaysia. The Quarterly Review of Economics and Finance, Forthcoming.

Ajmi, A.N., Hammoudeh, S., Nguyen, D.K., Sarafrazi, S., 2014. How strong are the causal relationships between Islamic stock markets and conventional financial systems? Evidence from linear and nonlinear tests. Journal of International Financial Markets, Institutions and Money, 28, pp. 213-227.

Akhtar, S.M., Akhtar, F., Jahromi, M., John, K., 2016. Intensity of volatility linkages in Islamic and conventional markets. Available at

SSRN: https://ssrn.com/abstract=2906546 or http://dx.doi.org/10.2139/ssrn.2906546.

Al-Khazali, O., Lean, H.H., Samet, A., 2014. Do Islamic stock indexes outperform conventional stock indexes? A stochastic dominance approach. Pacific-Basin Finance Journal, 28, pp. $29-46$. 
Al-Yahyaee, K.H., Mensi, W., Yoon, S.M., 2018. Efficiency, multifractality, and the long-memory property of the Bitcoin market: A comparative analysis with stock, currency, and gold markets. Finance Research Letters, 27, pp. 228-234.

Alam, N., Hassan, M.K., Haque, M.A., 2013. Are Islamic bonds different from conventional bonds? International evidence from capital market tests. Borsa Istanbul Review, 13(3), pp. 22-29.

Ali, R., Barrdear, J., Clews, R., Southgate, J., 2014. The economics of digital currencies. Bank of England Quarterly Bulletin, 54(3), pp. 276-286.

Ali, S., Shahzad, S.J.H., Raza, N., Al-Yahyaee, K.H., 2018. Stock market efficiency: A comparative analysis of Islamic and conventional stock markets. Physica A: Statistical Mechanics and its Applications, 503, pp. 139-153.

Aloui, C., Hammoudeh, S., Hamida, H.B., 2015a. Co-movement between sharia stocks and sukuk in the GCC markets: A time-frequency analysis. Journal of International Financial Markets, Institutions and Money, 34, pp. 69-79.

Aloui, C., Hammoudeh, S., Hamida, H.B., 2015b. Global factors driving structural changes in the co-movement between sharia stocks and sukuk in the Gulf Cooperation Council countries, The North American Journal of Economics and Finance, 31 pp. 311-329.

Aloui, C., Hkiri, B., Lau, C.K.M., Yarovaya, L., 2016. Investors' sentiment and US Islamic and conventional indexes nexus: A time-frequency analysis. Finance Research Letters, 19, pp. $54-59$.

Álvarez-Díaz, M., Hammoudeh, S., Gupta, R., 2014. Detecting predictable non-linear dynamics in Dow Jones Islamic Market and Dow Jones Industrial Average indices using nonparametric regressions. The North American Journal of Economics and Finance, 29, pp. 22-35.

Alzubaidi, I.B., Abdullah, A., 2017. Developing a digital currency from an Islamic perspective: Case of blockchain technology. International Business Research, 10(11), pp. 79-87.

Ashraf, D., Mohammad, N., 2014. Matching perception with the reality-Performance of Islamic equity investments. Pacific-Basin Finance Journal, 28, pp. 175-189.

Aysan, A.F., Demir, E., Gozgor, G., Lau, C.K.M., 2019. Effects of the geopolitical risks on Bitcoin returns and volatility. Research in International Business and Finance, 47, pp. 511-518.

Bakar, N.A., Rosbi, S., 2018. Robust Framework Diagnostics of Blockchain for Bitcoin Transaction System: A Technical Analysis from Islamic Financial Technology (i-FinTech) Perspective. International Journal of Business and Management, 2(3), pp. 22-29. 
Balcilar, M., Bouri, E., Gupta, R., Roubaud, D., 2017. Can volume predict Bitcoin returns and volatility? A quantiles-based approach. Economic Modelling, 64, pp. 74-81.

Baur, D.G., Hong, K., Lee, A.D., 2018. Bitcoin: Medium of exchange or speculative assets? Journal of International Financial Markets, Institutions and Money, 54, pp. 177- 189.

Baur, D.G., Lee, A.D., Hong, K., 2015. Bitcoin: Currency or Investment? SSRN Electronic Journal.

DOI:10.2139/ssrn.2561183.

Beck, T., Demirgüç-Kunt, A., Merrouche, O., 2013. Islamic vs. conventional banking: Business model, efficiency and stability. Journal of Banking \& Finance, 37, pp. 433-447.

Bouoiyour, J., Selmi, R., 2017. Are Trump and Bitcoin good partners? arXiv preprint arXiv:1703.00308. https://arxiv.org/abs/1703.00308

Bouri, E., Gupta, R., Tiwari, A.K., Roubaud, D., 2017a. Does Bitcoin hedge global uncertainty? Evidence from wavelet-based quantile-in-quantile regressions. Finance Research Letters, 23 , pp. 87-95.

Bouri, E., Jalkh, N., Molnár, P., Roubaud, D., 2017b. Bitcoin for energy commodities before and after the December 2013 crash: diversifier, hedge or safe haven? Applied Economics, 49(50), pp. 5063-5073.

Bouri, E., Molnár, P., Azzi, G., Roubaud, D., Hagfors, L.I., 2017c. On the hedge and safe haven properties of Bitcoin: Is it really more than a diversifier? Finance Research Letters, 20, pp. 192-198.

Briere, M., Oosterlinck, K., Szafarz, A., 2015. Virtual currency, tangible return: Portfolio diversification with bitcoin. Journal of Asset Management, 16(6), pp. 365-373.

Cheah, E.T., Fry, J., 2015. Speculative bubbles in Bitcoin markets? An empirical investigation into the fundamental value of Bitcoin. Economics Letters, 130, pp. 32-36.

Ciaian, P., Rajcaniova, M., Kancs, D.A., 2016. The economics of BitCoin price formation. Applied Economics, 48(19), pp. 1799-1815.

Cumming, D., Helge Haß, L., Schweizer, D., 2014. Strategic asset allocation and the role of alternative investments. European Financial Management, 20(3), pp. 521-547.

Dania, A., Malhotra, D.K., 2013. An empirical examination of the dynamic linkages of faith-based socially responsible investing. The Journal of Wealth Management, 16(1), pp. 65-79. 
Dewandaru, G., Rizvi, S.A.R., Masih, R., Masih, M., Alhabshi, S.O., 2014. Stock market comovements: Islamic versus conventional equity indices with multi-timescales analysis. Economic Systems, 38(4), pp. 553-571.

Dickey, D., Fuller, W., 1979. Distribution of the estimators for autoregressive time series with a unit root. Journal of the American Statistical Association, 74, pp. 427-431.

Dyhrberg, A.H., 2016a. Bitcoin, gold and the dollar-A GARCH volatility analysis. Finance Research Letters, 16, pp. 85-92.

Dyhrberg, A.H., 2016b. Hedging capabilities of bitcoin. Is it the virtual gold? Finance Research Letters, 16, pp. 139-144.

EconoTimes, 2016. Japans Cabinet Approves New Bitcoin Regulations. econotimes.com.

ElBahrawy, A., Alessandretti, L., Kandler, A., Pastor-Satorras, R., Baronchelli, A., 2017. Evolutionary dynamics of the cryptocurrency market. Royal Society Open Science, 4(11), 170623, pp. 1-9.

Elendner, H., Trimborn, S., Ong, B., Lee, T.M., 2016. The cross-section of crypto-currencies as financial assets: An overview (No. 2016-038). SFB 649 Discussion Paper.

Engle, R.F., 1982. Autoregressive conditional heteroscedasticity with estimates of the variance of United Kingdom inflation. Econometrica, 50(4), pp. 987-1007.

Evans, C.W., 2015. Bitcoin in Islamic banking and finance. Journal of Islamic Banking and Finance, 3(1), pp. 1-11.

Garcia, D., Tessone, C.J., Mavrodiev, P., Perony, N., 2014. The digital traces of bubbles: feedback cycles between socio-economic signals in the Bitcoin economy. Journal of the Royal Society Interface, 11(99), 20140623, pp. 1-8.

Girardi, G., Ergün, T., 2013. Systemic risk measurement: Multivariate GARCH estimation of CoVaR. Journal of Banking \& Finance, 37(8), pp. 3169-3180.

Godlewski, C.J., Turk-Ariss, R., Weill, L., 2013. Sukuk vs. conventional bonds: A stock market perspective. Journal of Comparative Economics, 41(3), pp. 745-761.

Hakim, S., Rashidian, S., 2002. How costly is investors' compliance to Sharia?. http://www.mafhoum.com/press7/220E11.pdf

Hansen, B.E., 1994. Autoregressive conditional density estimation. International Economic Review, 35, pp. 705-730. 
Hammoudeh, S., Mensi, W., Reboredo, J.C., Nguyen, D.K., 2014. Dynamic dependence of the global Islamic equity index with global conventional equity market indices and risk factors. Pacific-Basin Finance Journal, 30, pp. 189-206.

Hayat, R., Kraussl, R., 2011. Risk and return characteristics of Islamic equity funds. Emerging Markets Review, 12(2), pp. 189-203.

Hkiri, B., Hammoudeh, S., Aloui, C., Yarovaya, L., 2017. Are Islamic indexes a safe haven for investors? An analysis of total, directional and net volatility spillovers between conventional and Islamic indexes and importance of crisis periods. Pacific-Basin Finance Journal, 43, pp. 124-150.

Ho, C.S.F., Rahman, N.A.A., Yusuf, N.H.M., Zamzamin, Z., 2014. Performance of global Islamic versus conventional share indices: International evidence. Pacific-Basin Finance Journal, 28, pp. 110-121.

Hosking, J.R.M., 1981. Fractional differencing. Biometrika, 68, pp. 165-176.

Hussein, K., Omran, M., 2005. Ethical investment revisited: evidence from Dow Jones Islamic indexes. The Journal of Investing, 14(3), pp. 105-126.

Jawadi, F., Jawadi, N., Louhichi, W., 2014. Conventional and Islamic stock price performance: An empirical investigation. International Economics, 137, pp. 73-87.

Ji, Q., Bouri, E., Gupta, R., Roubaud, D., 2018. Network causality structures among Bitcoin and other financial assets: A directed acyclic graph approach. The Quarterly Review of Economics and Finance, 70, pp. 203-213.

Karim, B.A., Lee, W.S., Karim, Z.A., Jais, M., 2012. The impact of subprime mortgage crisis on Islamic banking and Islamic stock market. Procedia-Social and Behavioral Sciences, 65, pp. 668-673.

Kassab, S., 2013. Modeling volatility stock market using the ARCH and GARCH models: comparative study index (SP Sharia VS SP 500). European Journal of Banking and Finance, 10, pp. 72-77.

Kawa, L., 2015. Bitcoin Is Officially a Commodity, According to U.S. Regulator. Bloomberg.com.

Kenourgios, D., Naifar, N., Dimitriou, D., 2016. Islamic financial markets and global crises: Contagion or decoupling? Economic Modelling, 57, pp. 36-46.

Khuntia, S., Pattanayak, J.K., 2018. Adaptive long memory in volatility of intra-day bitcoin returns and the impact of trading volume. Finance Research Letters, Forthcoming. 
Kristoufek, L., 2015. What are the main drivers of the Bitcoin price? Evidence from wavelet $\begin{array}{llll}\text { coherence } & \text { analysis. } & \text { PloS } & \text { 10(4), }\end{array}$ https://doi.org/10.1371/journal.pone.0123923

Kwiatkowski, D., Phillips, P.C.B., Schmidt, P., Shim, Y., 1992. Testing the null hypothesis of stationarity against the alternative of a unit root: how sure are we that economic time series are non-stationary? Journal of Econometrics, 54, pp. 159-178.

Lahmiri, S., Bekiros, S., 2018. Time-varying self-similarity in alternative investments. Chaos, Solitons \& Fractals, 111, pp. 1-5.

Lahmiri, S., Bekiros, S., Stavroyiannis, S., Babalos, V., 2018. Modelling volatility persistence under stochasticity assumptions: Evidence from common and alternative investments. Chaos, Solitons \& Fractals, 114, pp. 158-163.

Lim, S.J., Masih, M., 2017. Exploring portfolio diversification opportunities in Islamic capital markets through bitcoin: Evidence from MGARCH-DCC and Wavelet approaches. MPRA paper 79752. https://mpra.ub.uni-muenchen.de/79752/

Liu, C., Zhou, Y., Sui, J., Wu, C., 2017. Multivariate frequency analysis of urban rainfall characteristics using three-dimensional copulas. Water Science \& Technology, 1, pp. 206218.

Maghyereh, A.I., Awartani, B., 2016. Dynamic transmissions between Sukuk and bond markets. Research in International Business and Finance, 38, pp. 246-261.

Maghyereh, A., Awartani, B., Hassan, A., 2018. Can gold be used as a hedge against the risks of Sharia-compliant securities? Application for Islamic portfolio management. Journal of Asset Management, 19(6), pp. 394-412.

Maghyereh, A.I., Abdoh, H., Awartani, B., 2019. Connectedness and hedging between gold and Islamic securities: A new evidence from time-frequency domain approaches. Pacific-Basin Finance Journal, 54, pp. 13-28.

Majdoub, J., Mansour, W., 2014. Islamic equity market integration and volatility spillover between emerging and US stock markets. The North American Journal of Economics and Finance, 29, pp. 452-470.

Mazouz, K., Mohamed, A., Saadouni, B., 2019. Price reaction of ethically screened stocks: A study of the Dow Jones Islamic Market World Index. Journal of Business Ethics, 154(3) pp. 117. 
Meera, A.K.M., 2018. Cryptocurrencies from Islamic perspectives: The case of Bitcoin. Bulletin of Monetary Economics and Banking, 20(4), pp. 475-492.

Mensi, W., Hammoudeh, S., Reboredo, J.C., Nguyen, D.K., 2015. Are Sharia stocks, gold and US Treasury hedges and/or safe havens for the oil-based GCC markets? Emerging Markets Review, 24, pp. 101-121.

Mensi, W., Rehman, M.Ur, Maitra, D., Al-Yahyaee, K.H., 2018. Does Bitcoin commove and share risk with Sukuk and Islamic stock indexes? Evidences using time-frequency approach. https://islamicmarkets.com/publications/does-bitcoin-comove-and-share-risk-withsukukand-islamic

Milly, M., Sultan, J., 2012. Portfolio diversification during financial crisis: Analysis of faith based investment strategies: In Building bridges across the financial communities: The global financial crisis, social responsibility, and faith-based finance (ss. 334-352), Harvard Law School, Islamic finance project (2012).

Moore, T., Christin, N., 2013, April. Beware the middleman: Empirical analysis of Bitcoinexchange risk. In International Conference on Financial Cryptography and Data Security (pp. 25-33). Springer, Berlin, Heidelberg.

Muedini, F., 2018. The Compatibility of Cryptocurrencies and Islamic Finance. European Journal of Islamic Finance, August (10), pp. 1-11. http://www.ojs.unito.it/index.php/EJIF/article/view/2569/pdf

Muli, A.M., Jagongo, A., 2019. Investment strategies, fund size and financial performance of defined contribution schemes in Kenya: Theoretical review. International Academic Journal of Economics and Finance, 3(3), pp. 253-265.

Naifar, N., 2016. Do global risk factors and macroeconomic conditions affect global Islamic index dynamics? A quantile regression approach. The Quarterly Review of Economics and Finance, 61, pp. 29-39.

Najeeb, S.F., Bacha, O., Masih, M., 2015. Does heterogeneity in investment horizons affect portfolio diversification? Some insights using M-GARCH-DCC and wavelet correlation analysis. Emerging Markets Finance and Trade, 51(1), pp. 188-208.

Nakamoto, S., 2008. Bitcoin: A peer-to-peer electronic cash system. https://bitcoin.org/bitcoin.pdf Narayan, P.K., Bannigidadmath, D., 2017. Does financial news predict stock returns? New evidence from Islamic and non-Islamic stocks. Pacific-Basin Finance Journal, 42, pp. 2445. 
Nazlioglu, S., Hammoudeh, S., Gupta, R., 2015. Volatility transmission between Islamic and conventional equity markets: Evidence from causality-in-variance test. Applied Economics, 47(46), pp. 4996-5011.

Patton, A.J., 2006. Modelling asymmetric exchange rate dependence. International Economic Review, 47(2), pp. 527-556.

Phillips, P.C.B., Perron, P., 1988. Testing for a unit root in time series regression. Biometrica, 75, pp. 335-346.

Reboredo, J.C., Ugolini, A., 2015. A vine-copula conditional value-at-risk approach to systemic sovereign debt risk for the financial sector. The North American Journal of Economics and Finance, 32, pp. 98-123.

Rehman, M.U., Apergis, N., 2019. Determining the predictive power between cryptocurrencies and real time commodity futures: Evidence from quantile causality tests. Resources Policy, 61, pp. 603-616.

Rizvi, S.A.R., Arshad, S., Alam, N., 2015. Crises and contagion in Asia Pacific-Islamic v/s conventional markets. Pacific-Basin Finance Journal, 34, pp. 315-326.

Rogojanu, A., Badea, L., 2014. The issue of competing currencies. Case study-Bitcoin. Theoretical \& Applied Economics, 21(1), pp. 103-114.

Saâdaoui, F., Naifar, N., Aldohaiman, M.S., 2017. Predictability and co-movement relationships between conventional and Islamic stock market indexes: A multiscale exploration using wavelets. Physica A: Statistical Mechanics and its Applications, 482, pp. 552-568.

Shahzad, S.J.H., Arreola-Hernandez, J., Bekiros, S., Shahbaz, M., Kayani, G.M., 2018. A systemic risk analysis of Islamic equity markets using vine copula and delta CoVaR modeling. Journal of International Financial Markets, Institutions and Money, 56, pp. 104-127.

Shahzad, S.J.H., Ferrer, R., Ballester, L., Umar, Z., 2017. Risk transmission between Islamic and conventional stock markets: A return and volatility spillover analysis. International Review of Financial Analysis, 52, pp. 9-26.

Shamsuddin, A., 2014. Are Dow Jones Islamic equity indices exposed to interest rate risk? Economic Modelling, 39, pp. 273-281.

Sklar, A., 1959. Fonctions de Répartition à n Dimensions et Leurs Marges. Publications de l'Institut Statistique de l'Université de Paris, 8, pp. 229-231.

Trimborn, S., Härdle, W.K., 2018. CRIX an index for blockchain based currencies. Journal of Empirical Finance, 49, pp. 107-122. 
Tschorsch, F., Scheuermann, B., 2016. Bitcoin and beyond: A technical survey on decentralized digital currencies. IEEE Communications Surveys \& Tutorials, 18(3), pp. 2084-2123.

Vigna, P., Casey, M.J., 2015. Cryptocurrency: how Bitcoin and digital money are challenging the global economic order. The Bodley Head, Random House, London.

Wahyudi, I., Sani, G.A., 2014. Interdependence between Islamic capital market and money market: Evidence from Indonesia. Borsa Istanbul Review, 14(1), pp. 32-47.

Wang, G.J., Xie, C., 2016. Tail dependence structure of the foreign exchange market: A network view. Expert Systems with Applications, 46, pp. 164-179.

Wang, S., Vergne, J.P., 2017. Buzz factor or innovation potential: What explains cryptocurrencies' returns? PloS one, 12(1), p.e0169556. https://doi.org/10.1371/journal.pone.0177659

Yermack, D., 2015. Is Bitcoin a real currency? An economic appraisal. In Handbook of digital currency (pp. 31-43). Academic Press.

Zhang, W., Wang, P., Li, X., Shen, D., 2018. The inefficiency of cryptocurrency and its crosscorrelation with Dow Jones Industrial Average. Physica A: Statistical Mechanics and its Applications, 510, pp. 658-670. 